\title{
Detection and Verification of QTL for Salinity Tolerance at Germination and Seedling Stages Using Wild Barley Introgression Lines
}

\author{
Mohammed Abdelaziz Sayed 1,2,*(D), Rasha Tarawneh ${ }^{2}$, Helmy Mohamed Youssef ${ }^{3,4}$ (D), Klaus Pillen 4 (i) and \\ Andreas Börner ${ }^{2, * \mathbb{D}}$ \\ 1 Agronomy Department, Faculty of Agriculture, Assiut University, Assiut 71526, Egypt \\ 2 Resources Genetics and Reproduction, Gene Bank, Leibniz Institute of Plant Genetics and Crop Plant \\ Research (IPK), OT Gatersleben, D-06466 Seeland, Germany; tarawneh@ipk-gatersleben.de \\ 3 Faculty of Agriculture, Cairo University, Giza 12613, Egypt; \\ helmy.mohamed-youssef-ibrahim@landw.uni-halle.de \\ 4 Plant Breeding, Institute of Agricultural and Nutritional Sciences, Martin-Luther-University Halle-Wittenberg, \\ Betty-Heimann-Str. 3, 06120 Halle, Germany; klaus.pillen@landw.uni-halle.de \\ * Correspondence: msayed@aun.edu.eg (M.A.S.); boerner@ipk-gatersleben.de (A.B.)
}

Citation: Sayed, M.A.; Tarawneh, R.; Youssef, H.M.; Pillen, K.; Börner, A. Detection and Verification of QTL for Salinity Tolerance at Germination and Seedling Stages Using Wild Barley Introgression Lines. Plants 2021, 10, 2246. https://doi.org/10.3390/ plants10112246

Academic Editor: Peter A. Roussos

Received: 28 September 2021

Accepted: 11 October 2021

Published: 21 October 2021

Publisher's Note: MDPI stays neutral with regard to jurisdictional claims in published maps and institutional affiliations.

Copyright: (c) 2021 by the authors. Licensee MDPI, Basel, Switzerland. This article is an open access article distributed under the terms and conditions of the Creative Commons Attribution (CC BY) license (https:/ / creativecommons.org/licenses/by/ $4.0 /)$.

\begin{abstract}
Salinity is one of the major environmental factors that negatively affect crop development, particularly at the early growth stage of a plant and consequently the final yield. Therefore, a set of 50 wild barley (Hordeum vulgare ssp. spontaneum, Hsp) introgression lines (ILs) was used to detect QTL alleles improving germination and seedling growth under control, $75 \mathrm{mM}$, and $150 \mathrm{mM} \mathrm{NaCl}$ conditions. Large variation was observed for germination and seedling growth related traits that were highly heritable under salinity stress. In addition, highly significant differences were obtained for five salinity tolerance indices and between treatments as well. A total of 90 and 35 significant QTL were identified for ten investigated traits and for tolerance indices, respectively. The Hsp introgression alleles are involved in improving salinity tolerance at forty $(43.9 \%)$ out of 90 QTL including introgression lines S42IL-109 (2H), S42IL-116 (4H), S42IL-132 (6H), S42IL-133 (7H), S42IL$148(6 \mathrm{H})$, and S42IL-176 (5H). Interestingly, seven exotic QTL alleles were successfully validated in the wild barley ILs including S42IL-127 (5H), $139(7 \mathrm{H}), 125(5 \mathrm{H}), 117(4 \mathrm{H}), 118(4 \mathrm{H}), 121(4 \mathrm{H})$, and $137(7 \mathrm{H})$. We conclude that the barley introgression lines contain numerous germination and seedling growth-improving novel QTL alleles, which are effective under salinity conditions.
\end{abstract}

Keywords: Hordeum spontaneum; salt-tolerance; early stages; introgression lines; quantitative trait loci (QTL)

\section{Introduction}

Salinity, together with drought, is a serious constraint to food security in many parts of the world due to it suppressing plant growth, development, and crop productivity, and restricting the use of agricultural land. However, about $20 \%$ of total cultivated and $33 \%$ of irrigated agricultural lands are afflicted by high salt stress, and the salinity problem is predicted to be increased annually by $10 \%$ due to various reasons, including poor irrigation management and climatic change, which causes low precipitation and high surface evaporation [1-3], especially as $92 \%$ of the salt-affected areas are located in the regions with arid climate [4]. Pirasteh-Anosheh et al. [5] pointed out that plants are exposed to four different types of salinity effects under salt conditions: briefly (1) soil salinity reduces water uptake of a plant due to low soil water potential, which interferes with the osmotic gradient [6]; (2) salinity accelerates the production of active oxygen radicles, like hydrogen peroxide, superoxide, singlet oxygen, and hydroxyl radicle, which may damage or kill plants [7]; (3) the salt interacts with minerals, causing nutrient imbalance and deficiency [8]; 
and (4) the absorbed salt reaches a level that causes severe cellular toxicity due to low sequestration of $\mathrm{Na}^{+}$into vacuoles [8].

Barley, the fourth most leading cereal crop worldwide, is one of the main winter cereals in the Mediterranean region [9]. Barley is relatively salt-tolerant and has the advantage of growing in marginal environments that are unsuitable for other cereal crops $[9,10]$. Therefore, it is oftentimes used as a model plant for understanding salinity adaptation mechanisms in crops and for studying the germination in monocots [11,12]. However, salinity causes a significant reduction in its growth and grain yield. The adaptation of barley to salt stress differs from one growth stage to another, where the germination and the early development stages of plant growth are considered the most sensitive ones. Many studies investigated the effect of salt stress on barley seed germination and seedling development to determine the effect of salinity on plants and develop salt-tolerant accessions for breeding programs $[10,13,14]$. A clear reduction in germination percentage, rate, shoot length, root length, root fresh and dry weights, and relative growth rate was reported by increasing salinity levels in barley [10,13-17].

During the current climate change conditions, crop improvement efforts to abiotic stresses face a great challenge. Therefore, a deeper understanding of crop genetic resources is needed, if these assets contribute effectively in developing improved varieties [18]. Wild barley (Hordeum vulgare ssp. spontaneum Koch, $\mathrm{Hsp}$ ) has developed unique mechanisms for surviving harsh environments, mainly through forming new genetic variations and alleles [19]. Among various mapping strategies, introgression lines (ILs) breeding is an effective method for improving barley and expanding genetic diversity to meet present and future challenges to crop production [18]. The ILs produced by advanced backcrossing carry only a small introgression of a wild donor parent and represent the complete genome of a wild donor species, which could be utilized as an immortal QTL mapping population [20]. Additionally, $\mathrm{Hsp}$ has a great potentiality in barley improvement as a donor in the introgression libraries, since positional cloning of natural QTL plays a prevailing role in elucidating the molecular control of abiotic stresses tolerance such as drought and salinity [19]. In this way, by using genetic approaches, new genes and/or new alleles associated with enhanced salinity tolerance at known loci present in wild genotypes could be mapped and targeted for introgression. In the past decade, a number of studies have investigated the S42ILs library under different environmental conditions including drought, phosphorus and nitrogen deficiency [21-26]. These experiments identified beneficial exotic QTL alleles, which were contributed significantly to the enhancement of agronomic, biotic, and abiotic stress tolerance-related traits. Further, they concluded that beneficial wild barley QTL alleles are present in the S42ILs library, which could be used to select for improved interesting traits in barley breeding. The present work is considered the first QTL study, conducted under control and salinity stress by applying different $\mathrm{NaCl}$ concentrations (75 and $150 \mathrm{mM}$ ) at germination and seedling stages using a set of wild barley ILs. Our study aimed at (1) detecting the QTL in the S42IL library associated with salinity tolerance at germination and seedling stages, (2) finding the desirable Hsp alleles that improve trait performances under salinity conditions, and (3) verifying and comparing the obtained QTL with previously mapped QTL of a field trial conducted in Egypt under severe salinity conditions using $\mathrm{S} 42$ barley population.

\section{Results}

\subsection{Variations and Heritability}

The analysis of variance revealed highly significant differences between genotypes tested for all measured traits under control and salinity conditions at germination and seedling stages (Table 1). Additionally, the combined ANOVA revealed that all effects of genotypes, treatments, and genotype by treatment interactions effects were highly significant for all studied traits. Further, in most cases, coefficients of variations increased by increasing salt concentrations. The genotypes exhibited significant differences in seed viability tested before experiment initiation. As an average of all genotypes, the seed 
viability was $85 \%$, ranging between 65 and $100 \%$. In addition, moderate to high values of coefficient of determination $\left(\mathrm{R}^{2}\right)$ and heritability $\left(\mathrm{H}_{\mathrm{b}}\right)$ estimates were obtained under control and salinity stress conditions. For instance, the highest $\mathrm{R}^{2}$ and $\mathrm{H}_{\mathrm{b}}$ estimates were found for GI, ShL, and SL under control, $75 \mathrm{mM} \mathrm{NaCl}$, and $150 \mathrm{mM} \mathrm{NaCl}$ treatments, respectively. Whereas RSR, MGT, and WCP revealed the lowest estimates of $\mathrm{R}^{2}$ and $\mathrm{H}_{\mathrm{b}}$ under the previous conditions, respectively.

\subsection{Trait Means and Reduction Percentage}

Trait means, and ranges under control and salinity conditions as well as reduction percentage ( $\mathrm{R} \%$ ) due to salinity compared to control are presented in Table 2. Most of the investigated traits were declined by increasing salt concentrations compared to control, except RSR and SDW were increased under $150 \mathrm{mM} \mathrm{NaCl}$ treatment by 54.5 and $23.4 \%$, respectively, compared to control. For example, as an average overall genotypes, the means values of GP (Figure 1A) were 89.9, 80.3, and 79.6\%; ShL means were 9.5, 6, and $4.1 \mathrm{~cm}$; RL means (Figure 1F) were 10.6, 8, and $6.2 \mathrm{~cm}$; and WCP means (Figure 1K) were 89, 87.9, and $79 \%$ under control, $75 \mathrm{mM} \mathrm{NaCl}$, and $150 \mathrm{mM} \mathrm{NaCl}$ treatments, respectively. In addition, maximum $\mathrm{R} \%$ under $75 \mathrm{mM} \mathrm{NaCl}$ treatment was observed for SVI (-37.1\%) followed by ShL $(-36.8 \%)$, while WCP $(-2.1 \%)$ exhibited the minimum R\%. Similarly, under $150 \mathrm{mM}$ $\mathrm{NaCl}$ treatment, the maximum $\mathrm{R} \%$ were obtained from ShL $(-56.8 \%)$ followed by SVI $(-55.4 \%)$, whereas minimum $\mathrm{R} \%$ was recorded for MGT $(-3.2 \%)$.

As an average under control, Scarlett showed significant superiority in GP (93.3\%), MGT (2.6), SVI (1986), ShL (9.9 cm), RL (11.3 cm), SL ( $21.3 \mathrm{~cm})$, SFW (278.7 mg), and WCP (90.3\%) compared to the S42Ils set, which accounted 89.7\%, 3.1, 1795, $9.4 \mathrm{~cm}, 10.6 \mathrm{~cm}, 20 \mathrm{~cm}$, $252.5 \mathrm{mg}$, and $89 \%$ for the same traits, respectively. Whereas, under $150 \mathrm{mM} \mathrm{NaCl}$ conditions, the S42IL set had better values in GP (79.6\%), GI (59.3), MGT (3 days), SVI (799.8), RL (6 cm), RSR (1.7), and SDW (34.4 mg) compared to Scarlett (Supplementary Table S1). Many S42ILs showed remarkable GP and SVI under control and salinity conditions compared to Scarlett, like S42IL-109, S42IL-112, S42IL-116, S42IL-117, S42IL-122, and S42IL-128. Similarly, lines S42IL-106, S42Il-111, S42IL-118, and S42IL-122 had higher GI and better MGT compared to Scarlett under the higher level of salinity. Interestingly, the ILs S42IL-109, S42IL-132, and S42IL-176 exhibited remarkable superiority in ShL, RL, and SL under both salinity treatments compared to Scarlett. They recorded $(9.6,6.6$, and $7.2 \mathrm{~cm})$ and $(7.7,7.6$, and $7 \mathrm{~cm})$ for ShL, $(9.7,8.2$, and $9.9 \mathrm{~cm})$ and $(7.3,7.4$, and 7.5$)$ for $\mathrm{RL}$, and $(19.2,14.8$, and $17 \mathrm{~cm})$ and $(15,15.1$, and $14.6 \mathrm{~cm})$ for SL under $75 \mathrm{mM} \mathrm{NaCl}$ and $150 \mathrm{mM} \mathrm{NaCl}$ treatments, respectively. Several ILs showed remarkable values of RSR under salinity treatments compared to Scarlett, for instance, S42 IL-125 and S42 IL-127 registered 2.6 and 4.1 as the highest RSR under 75 and $150 \mathrm{mM} \mathrm{NaCl}$ treatments, respectively. Under severe salinity conditions, the ILs S42 IL-132, S42 IL-109, and S42 IL-120 gave the highest SFW and recorded 241.8, 224.7, and $217.2 \mathrm{mg}$ compared to Scarlett, which gave $172 \mathrm{mg}$. For SDW, the ILs S42 IL-132, S42 IL-126, and S42 IL-120 were the best in SDW and gave 45.5, 43.3, and $42.6 \mathrm{mg}$ compared to Scarlett, which recorded $33.5 \mathrm{mg}$. Additionally, the ILs S42IL-109 and S42 IL-148 had higher WCP by 92.1 and $83.9 \%$ under 75 and $150 \mathrm{mM} \mathrm{NaCl}$ treatments, respectively. 


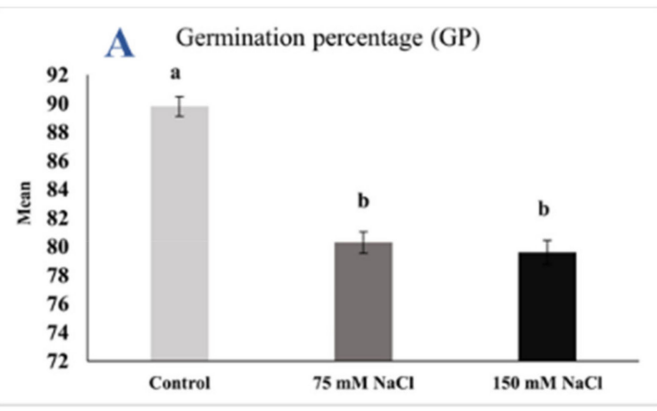

B Germination index (GI)
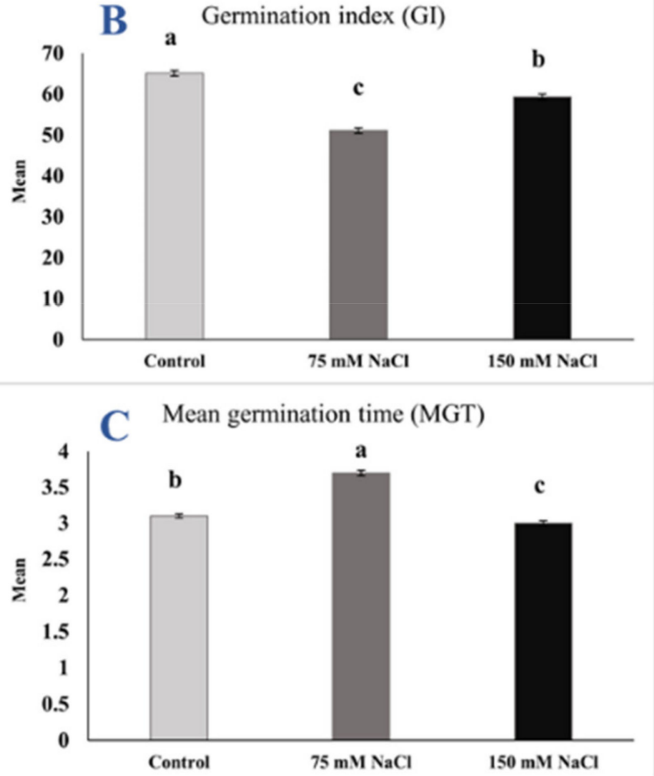

D Seedling vigour index (SVI)

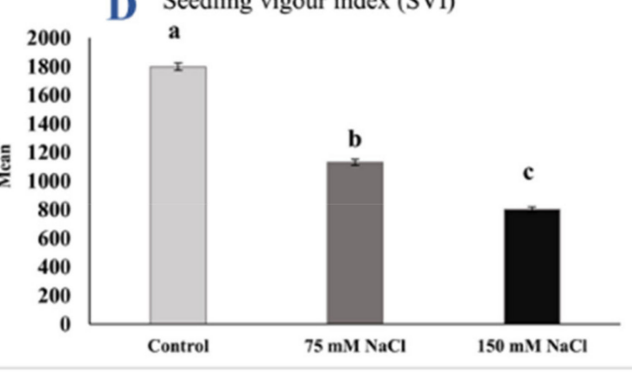

E Shoot length (ShL)
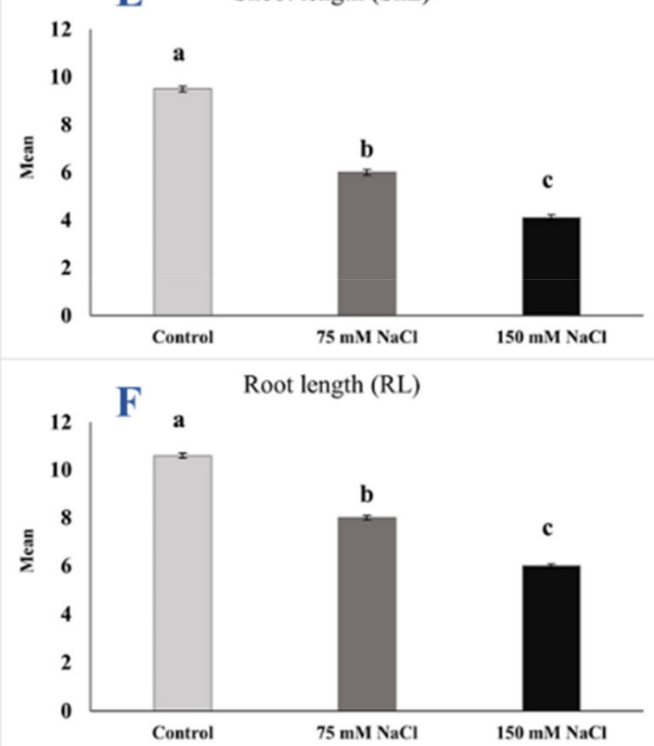

G Root:shoot ratio (RSR)

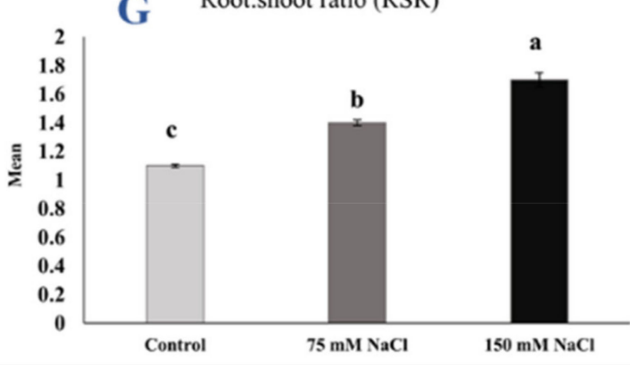

H Seedling length (SL)

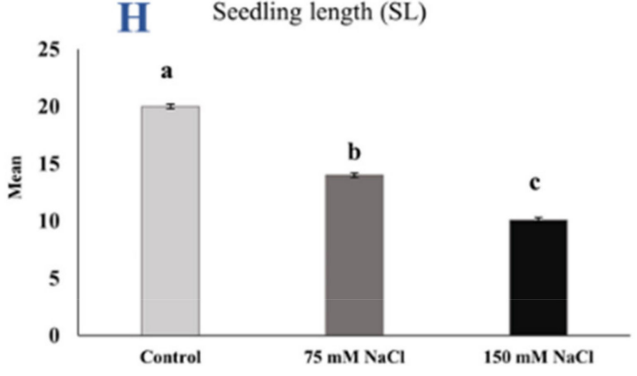

Seedling fresh weight (SFW)

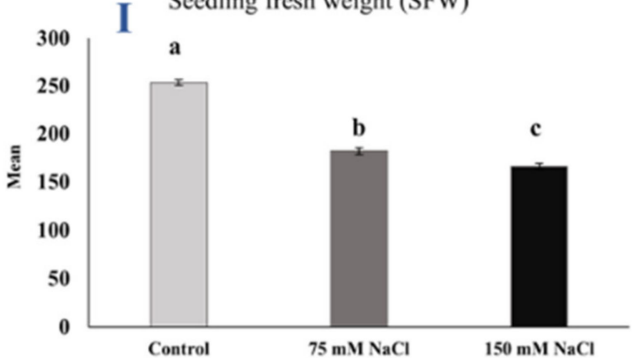

J Seedling dry weight (SDW)
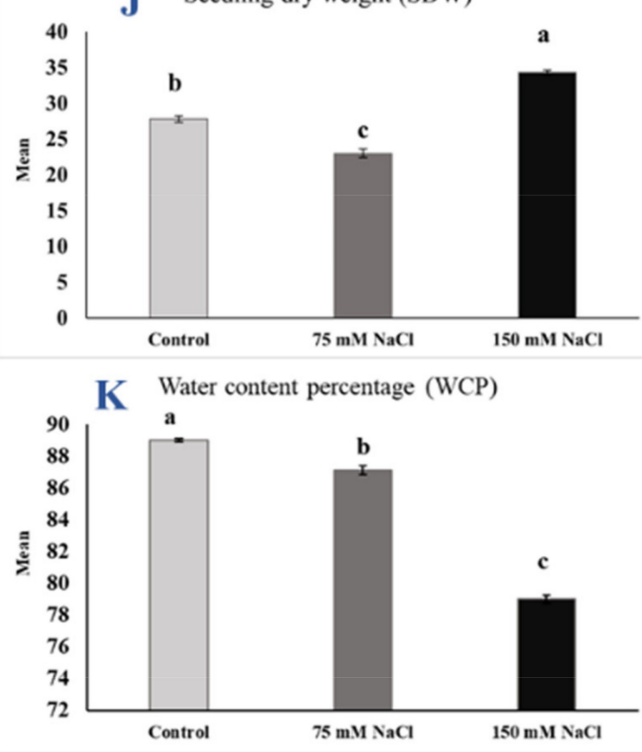

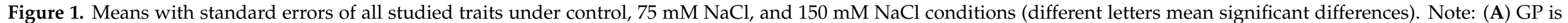

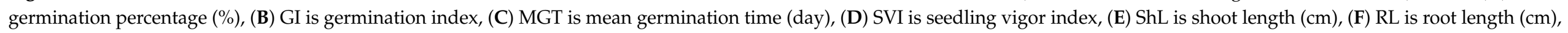
(G) RSR is root:shoot ratio, $(\mathbf{H})$ SL is seedling length $(\mathrm{cm})$, (I) SFW is seedling fresh weight (mg), (J) SDW is seedling dry weight (mg), and (K) WCP is water content percentage $(\%)$. 


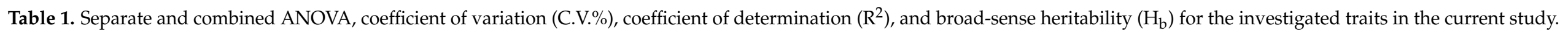

\begin{tabular}{|c|c|c|c|c|c|c|c|c|c|c|c|c|c|c|c|}
\hline \multirow{2}{*}{ Trait } & \multicolumn{3}{|l|}{ Control } & \multicolumn{3}{|c|}{$75 \mathrm{mM} \mathrm{NaCL}$} & \multicolumn{4}{|c|}{$150 \mathrm{mM} \mathrm{NaCL}$} & \multicolumn{5}{|c|}{ Combined ANOVA } \\
\hline & MS & C.V.\% & $\mathbf{R}^{2}$ & $\mathbf{H}_{\mathrm{b}}$ & MS & C.V.\% & $\mathbf{R}^{2}$ & $\mathbf{H}_{\mathrm{b}}$ & MS & C.V.\% & $\mathbf{R}^{2}$ & $\mathbf{H}_{\mathrm{b}}$ & G & $\mathrm{T}$ & $G \times T$ \\
\hline GP & $172.49 * *$ & 5.5 & 0.78 & 85.98 & $196.75^{* *}$ & 7.2 & 0.74 & 82.98 & $244.55^{* *}$ & 8.1 & 0.74 & 83.02 & $346.6^{* *}$ & $148.8^{* *}$ & 133.6 ** \\
\hline GI & $200.3^{* *}$ & 5.0 & 0.90 & 94.71 & $145.96^{* *}$ & 10.3 & 0.72 & 81.14 & $174.22 * *$ & 10.4 & 0.69 & 78.01 & $277.7 * *$ & $7583 * *$ & 121.4 \\
\hline MGT & $0.47^{* *}$ & 5.5 & 0.88 & 93.62 & $0.54^{* *}$ & 9.9 & 0.66 & 75.02 & $0.34^{* *}$ & 9.2 & 0.68 & 77.36 & $0.44^{* *}$ & $20.5^{* *}$ & $0.46^{* *}$ \\
\hline SVI & $190,565^{* *}$ & 10.9 & 0.71 & 80.00 & $166,431^{* *}$ & 11.9 & 0.82 & 89.05 & $134,821 * *$ & 13.4 & 0.85 & 91.38 & $163,643^{* *}$ & $39,506,781^{* *}$ & $164,087^{* *}$ \\
\hline ShL & $4.44^{* *}$ & 11.2 & 0.66 & 74.76 & $6.44^{* *}$ & 13.1 & 0.83 & 90.24 & $6.79 * *$ & 16.8 & 0.87 & 92.98 & $5.1 * *$ & $1120.1^{* *}$ & $6.3^{* *}$ \\
\hline RL & $4.15^{* *}$ & 10.5 & 0.62 & 70.40 & $2.66^{* *}$ & 9.9 & 0.67 & 76.18 & $2.98^{* *}$ & 10.5 & 0.79 & 86.85 & $3.02 * *$ & $815.1^{* *}$ & $3.4^{* *}$ \\
\hline RSR & 0.02 ** & 11.0 & 0.42 & 30.92 & 0.24 ** & 13.1 & 0.78 & 86.41 & 1.03 ** & 21.5 & 0.80 & 87.63 & $0.47^{* *}$ & $10.6^{* *}$ & $0.41^{* *}$ \\
\hline SFW & $2166.4^{* *}$ & 12.0 & 0.53 & 57.39 & $3972.9 * *$ & 16.9 & 0.67 & 76.37 & $2749.5^{* *}$ & 14.3 & 0.70 & 79.39 & $2875.9^{* *}$ & $328,179 * *$ & $3006.5^{* *}$ \\
\hline SDW & $48.32 * *$ & 18.0 & 0.49 & 48.59 & $102.15^{* *}$ & 21.4 & 0.67 & 76.27 & $77.80 * *$ & 17.7 & 0.51 & 52.65 & $63.5^{* *}$ & $4981.3^{* *}$ & $82.4^{* *}$ \\
\hline WCP & $5.66^{* *}$ & 1.4 & 0.63 & 71.09 & $26.47^{* *}$ & 2.4 & 0.75 & 83.37 & $18.00^{* *}$ & 3.2 & 0.57 & 63.69 & $14.5^{* *}$ & $4294.6^{* *}$ & $17.8^{* *}$ \\
\hline SVP & 123.50 * & 6.5 & 0.66 & 74.99 & & & & & & & & & & & \\
\hline
\end{tabular}

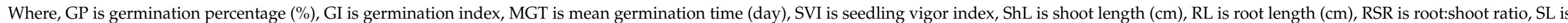

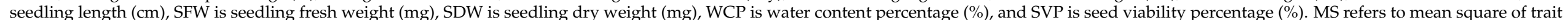
interest, $\mathrm{G}$ is genotype, $\mathrm{T}$ is treatment, and $\mathrm{G} \times \mathrm{T}$ is genotype by treatment interaction. ${ }^{*}$ and ${ }^{* *}$ significant and highly significant at 0.05 and 0.01 probability levels, respectively. 
Table 2. Summary statistics and reduction percentage (R\%) due to salinity effects on the studied traits as compared to control.

\begin{tabular}{|c|c|c|c|c|c|c|c|c|c|}
\hline \multirow{2}{*}{ Trait } & \multicolumn{2}{|c|}{ Control } & \multicolumn{3}{|c|}{$75 \mathrm{mM} \mathrm{NaCl}$} & \multicolumn{4}{|c|}{$150 \mathrm{mM} \mathrm{NaCl}$} \\
\hline & Mean \pm S.E. & Range & Mean \pm S.E. & Range & $\mathrm{R}^{\mathrm{a}}$ & Mean \pm S.E. & Range & $\mathbf{R} \% \mathbf{b}$ & $R \%{ }^{c}$ \\
\hline GP & $89.8 \pm 0.69$ & $60-100$ & $80.3 \pm 0.75$ & $60-100$ & -10.6 & $79.6 \pm 0.84$ & $53.3-100$ & -11.4 & -0.9 \\
\hline GI & $65.1 \pm 0.69$ & $45-85$ & $51.1 \pm 0.65$ & $33-68$ & -21.5 & $59.3 \pm 0.73$ & $37-79$ & -8.9 & 16.0 \\
\hline MGT & $3.1 \pm 0.03$ & $2.3-4.2$ & $3.7 \pm 0.04$ & $2.45-5.08$ & 19.4 & $3.3 \pm 0.03$ & $2-4.36$ & -3.2 & -18.9 \\
\hline SVI & $1799.1 \pm 24.01$ & $1026-2470$ & $1132 \pm 20.9$ & 553.3-1800 & -37.1 & $801.6 \pm 18.4$ & 271.1-1466.6 & -55.4 & -29.2 \\
\hline ShL & $9.5 \pm 0.12$ & $5-13.7$ & $6 \pm 0.12$ & $2.2-10.47$ & -36.8 & $4.1 \pm 0.12$ & $0.6-8$ & -56.8 & -31.7 \\
\hline RL & $10.6 \pm 0.11$ & $6.5-15.33$ & $8 \pm 0.09$ & $4.7-11.1$ & -24.5 & $6 \pm 0.09$ & $2.83-8.33$ & -43.4 & -25.0 \\
\hline RSR & $1.1 \pm 0.01$ & $0.8-1.67$ & $1.4 \pm 0.02$ & $0.91-3$ & 27.3 & $1.7 \pm 0.05$ & $0.91-5.56$ & 54.5 & 21.4 \\
\hline SL & $20 \pm 0.22$ & $12.2-29$ & $14 \pm 0.20$ & $8.3-20.33$ & -30 & $10.1 \pm 0.21$ & $3.83-15.6$ & -49.5 & -27.9 \\
\hline SFW & $253 \pm 2.95$ & $165.7-351.7$ & $181.8 \pm 3.55$ & $58.4-272$ & -28.2 & $166.1 \pm 2.89$ & $35.3-241.7$ & -34.4 & -8.6 \\
\hline SDW & $27.8 \pm 0.46$ & $12.8-43.5$ & $23 \pm 0.57$ & $7.6-40.5$ & -17.3 & $34.3 \pm 0.34$ & $11.93-48.97$ & 23.4 & 49.1 \\
\hline WCP & $89 \pm 0.13$ & $86.4-94.9$ & $87.1 \pm 0.27$ & $80.2-92.7$ & -2.1 & $79 \pm 0.25$ & $61.68-87.29$ & -11.2 & -9.3 \\
\hline SVP & $85 \pm 0.63$ & 65-100 & & & & & & & \\
\hline
\end{tabular}

Where, GP is germination percentage (\%), GI is germination index, MGT is mean germination time (day), SVI is seedling vigor index, ShL is shoot length $(\mathrm{cm})$, RL is root length $(\mathrm{cm})$, RSR is root: shoot ratio, SL is seedling length $(\mathrm{cm})$, SFW is seedling fresh weight $(\mathrm{mg})$, SDW is seedling dry weight (mg), WCP is water content percentage (\%), and SVP is seed viability percentage $(\%)$. R $\%^{a}$ and $\mathrm{R} \%{ }^{\mathrm{b}}$ are reduction percentages for all studied traits occurred in $75 \mathrm{mM}$ and $150 \mathrm{mM} \mathrm{NaCl}$ treatments compared to control treatment. $\mathrm{R} \%{ }^{\mathrm{c}}$ refers to reduction percentage occurred in $150 \mathrm{mM} \mathrm{NaCl}$ compared to $75 \mathrm{mM} \mathrm{NaCl}$ treatment.

\subsection{Phenotypic Correlation among Studied Traits}

Pearson correlation coefficients were calculated among the studied traits only under control and $150 \mathrm{mM} \mathrm{NaCl}$ treatments, and are displayed in Figure 2. Under both treatments, GP was positively and highly significantly correlated with GI and SVI. ShL showed highly significant and positive correlations with SVI (0.77 and 0.88), RL (0.82 and 0.83), SL (0.96 and 0.97$)$, SFW (0.65 and 0.89), and WCP (0.44 and 0.89) under control and $150 \mathrm{mM} \mathrm{NaCl}$ treatments, respectively. Additionally, RL exhibited significant and positive correlations with SL (0.95), SFW (0.63), and WCP (0.41) under control treatment. Whereas under 150 $\mathrm{mM} \mathrm{NaCl}$ treatments, it showed highly significant and positive correlations with SL (0.94), SFW (0.89), SDW (0.75), and WCP (0.56) and negative with RSR (-0.63). Correlations between shoot- and root-related traits were large under salinity conditions compared to control. The seed viability test was carried out before the start of the experiment, therefore, the correlation coefficients between germination and seedling growth-related traits and viability percentage (SVP) were at control treatment. SVP was significantly correlated with GP, GI, and SVI.

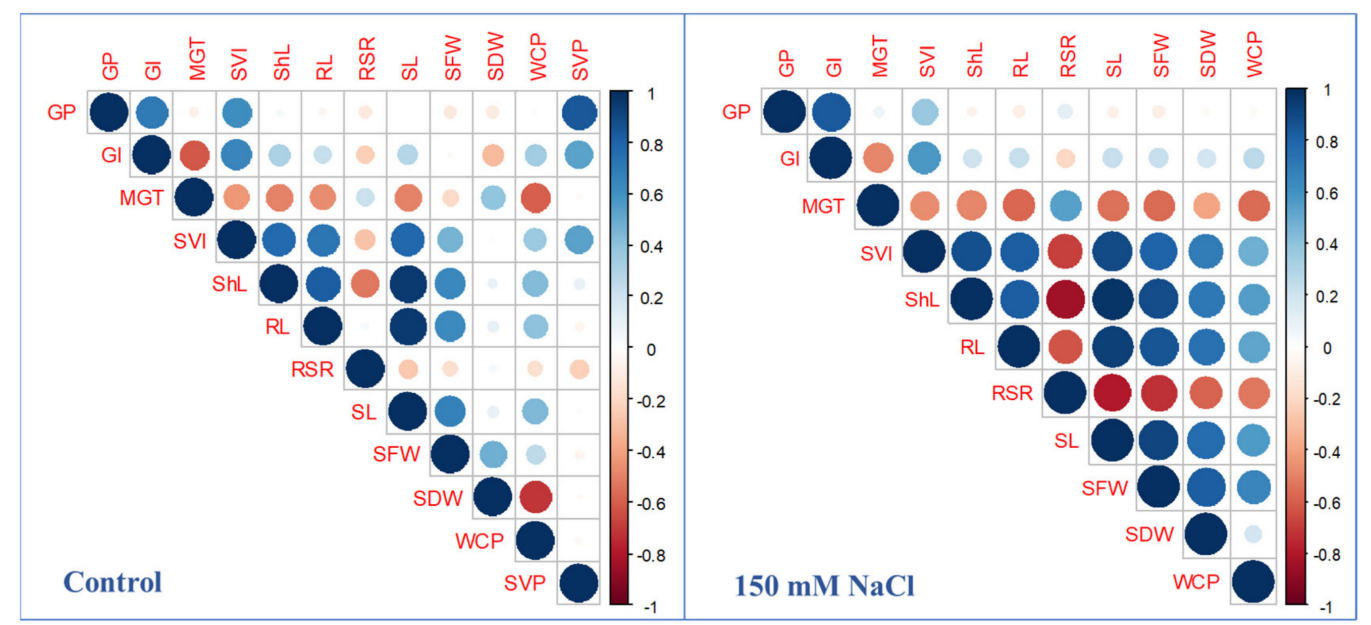

Figure 2. Pearson correlation coefficients among studied traits under control (left) and $150 \mathrm{mM} \mathrm{NaCl}$ conditions (right). Where, GP is germination percentage (\%), GI is germination index, MGT is mean germination time (day), SVI is seedling vigor index, ShL is shoot length (cm), RL is root length $(\mathrm{cm})$, RSR is root: shoot ratio, SL is seedling length $(\mathrm{cm}), \mathrm{SFW}$ is seedling fresh weight $(\mathrm{mg}), \mathrm{SDW}$ is seedling dry weight $(\mathrm{mg}), \mathrm{WCP}$ is water content percentage (\%), and SVP is seed viability percentage (\%). 


\subsection{Salinity Tolerance Indices}

Five salinity tolerance indices related to GP, SL, SFW, SDW, and WCP were subjected to the analysis of variance between control and each of $75 \mathrm{mM} \mathrm{NaCl}$ and $150 \mathrm{mM} \mathrm{NaCl}$ treatments (Table 3). Highly significant differences between genotypes were obtained for all salinity tolerance indices in control against both the 75 and $150 \mathrm{mM} \mathrm{NaCl}$ treatments. In addition, the highest heritability estimate was found for SLTI ( 85.8 and $88.1 \%$ ) for both comparison, respectively. Additionally, the mean values of salinity tolerance indices ranged between 0.72 (SLTI) and 0.98 (WCTI) when control was compared to $75 \mathrm{mM} \mathrm{NaCl}$ treatment, while it ranged between 0.52 (SLTI) and 1.31 (SDWTI). The lines S42IL-126, S42IL-132, and S42IL-136 recorded the highest STI for GP in both comparisons as control against $75 \mathrm{mM}$ $\mathrm{NaCl}$ and $150 \mathrm{mM} \mathrm{NaCl}$ compared to Scarlett (Supplementary Table S2). Similarly, lines S42IL-109, S42IL-114, and S42IL-176 were the best lines that showed remarkable STI for seedling length (SL) in both comparisons compared to Scarlett. For SFW, S42IL-109 gave the highest value of SFWTI when control was compared to 75 and $150 \mathrm{mM} \mathrm{NaCl}$ treatments, which recorded 1.15 and 1.06, respectively. Meanwhile, lines S42IL-133, S42IL-137, S42IL142, S42IL-138, and S42IL-176 were amongst lines that revealed higher SDWTI more than unity as compared to Scarlett in both comparisons. For WCP, lines S42IL-148, S42IL-109, S42IL-103, and S42IL-132 were amongst lines that showed superiority in WCTI as compared to Scarlett in both comparisons.

Table 3. Mean squares (MS), coefficient of determination $\left(\mathrm{R}^{2}\right)$, and broad-sense heritability $\left(\mathrm{H}_{\mathrm{b}}\right)$, means \pm standard error (S.E.), coefficient of variation (C.V.\%), and range for five salinity tolerance indices related to germination and seedling traits as comparison between control and salinity treatments.

\begin{tabular}{|c|c|c|c|c|c|c|}
\hline & \multicolumn{3}{|c|}{ Control-75 mM NaCl } & \multicolumn{3}{|c|}{ Control-150 mM NaCl } \\
\hline & MS & $\mathrm{R}^{2}$ & $\mathrm{H}_{\mathrm{b}}$ & MS & $\mathrm{R}^{2}$ & $\mathrm{H}_{\mathrm{b}}$ \\
\hline GTI & $0.0288 * *$ & 0.67 & 75.68 & $0.0327^{* *}$ & 0.68 & 77.30 \\
\hline SLTI & $0.0886^{* *}$ & 0.78 & 85.88 & $0.0683^{* *}$ & 0.81 & 88.17 \\
\hline SFWTI & $0.0856^{* *}$ & 0.64 & 72.86 & $0.0682 * *$ & 0.61 & 69.06 \\
\hline SDWTI & $0.2550 * *$ & 0.64 & 72.54 & 0.3020 ** & 0.49 & 48.21 \\
\hline \multirow[t]{2}{*}{ WCTI } & $0.0046^{* *}$ & 0.75 & 83.49 & $0.0030^{* *}$ & 0.62 & 69.60 \\
\hline & Mean \pm S.E. & C.V.\% & Range & Mean \pm S.E. & C.V.\% & Range \\
\hline GTI & $0.90 \pm 0.01$ & 9.3 & $0.66-1.25$ & $0.89 \pm 0.01$ & 9.7 & $0.62-1.25$ \\
\hline SLTI & $0.72 \pm 0.016$ & 15.6 & $0.37-1.56$ & $0.52 \pm 0.01$ & 17.4 & $0.17-1.16$ \\
\hline SFWTI & $0.73 \pm 0.017$ & 20.8 & $0.19-1.39$ & $0.68 \pm 0.015$ & 21.5 & $0.12-1.27$ \\
\hline SDWTI & $0.87 \pm 0.029$ & 26.5 & $0.29-2.33$ & $1.31 \pm 0.036$ & 30.2 & $0.34-30.47$ \\
\hline WCTI & $0.98 \pm 0.004$ & 2.8 & $0.89-1.06$ & $0.89 \pm 0.003$ & 3.5 & $0.69-1.01$ \\
\hline
\end{tabular}

Where, GTI is germination tolerance index, SLTI is seedling tolerance index, SFWTI is seedling fresh weight tolerance index, SDWTI is seedling dry weight tolerance index, and WCTI is water content tolerance index. ${ }^{* *}$ highly significant at 0.01 probability level.

\subsection{QTL Identification for Germination and Seedling Related Traits}

Altogether, 90 significant QTL effects were identified for ten germination- and seedlingrelated traits distributed over the entire barley genome (Supplementary Table S3 and Figure 3). Additionally, five QTL were detected for seed viability (Supplementary Table S3). Among these, 49 QTL showed introgression line by treatment interaction $(p<0.01)$, ten QTL showed line main effect $(p<0.05)$, and 31 showed both effects. In the following lines, we will present the most important results of QTL detection (Table 4). 


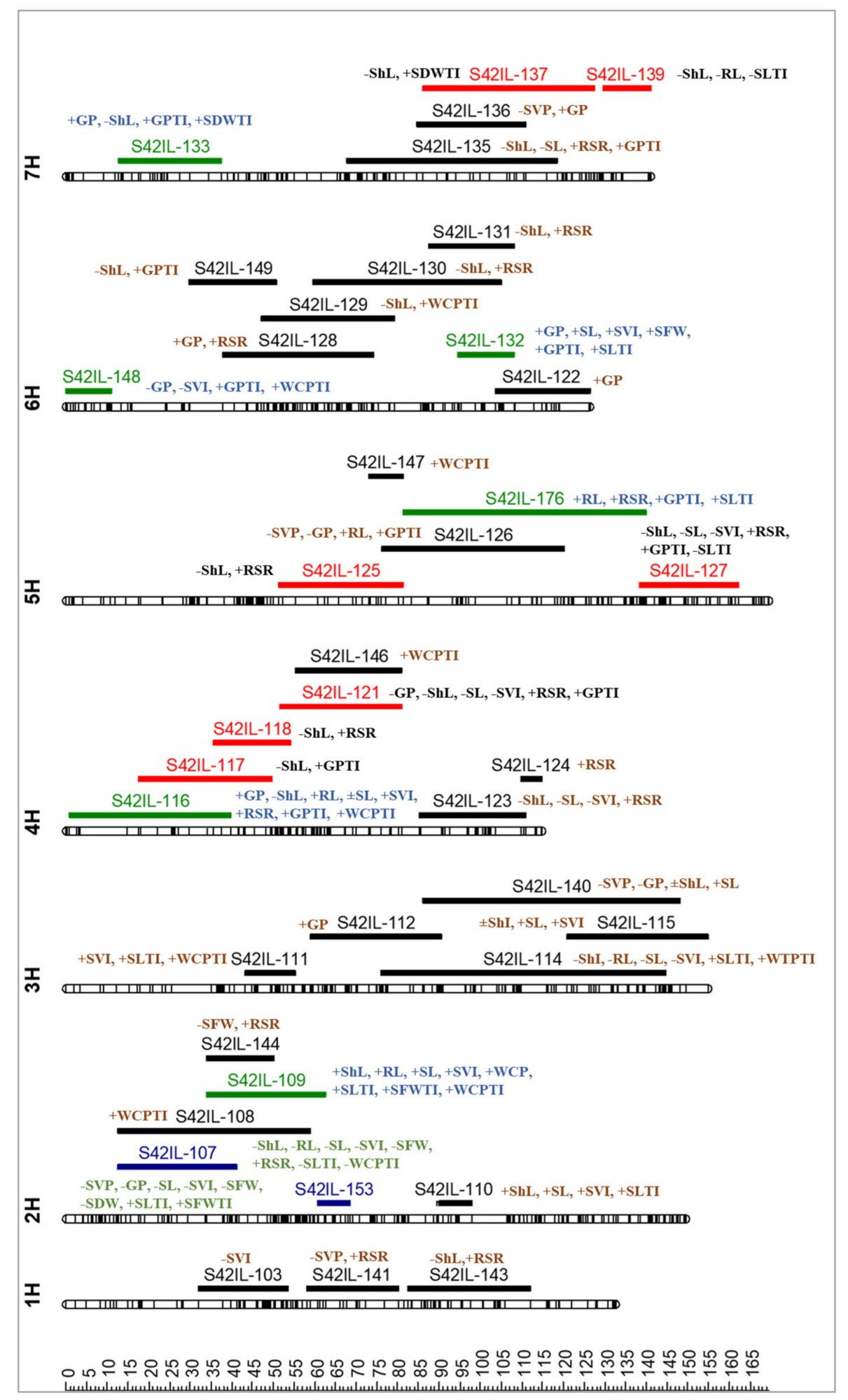

Figure 3. Localization of the most significant QTL in the S42ILs associated with germination- and seedling growth-related traits under control and salinity treatments. QTL are placed around the S42ILs, indicated by trait abbreviations. The sign indicates an increasing (+) or decreasing (-) $H s p$ effect. Green ILs indicate the most favorable effects of Hsp alleles, blue ILs indicate the most unfavorable effects of Hsp alleles, and red ILs indicate verified and validated QTL with previously published QTL in adult barley plants. 
Table 4. Identification of putative QTL associated with salinity tolerance related traits at germination and seedling stages as line main effect and line by treatment interaction.

\begin{tabular}{|c|c|c|c|c|c|c|c|c|c|c|c|c|}
\hline \multirow{2}{*}{ Trait } & \multirow{2}{*}{ QTL } & \multirow{2}{*}{ Int. Lines } & \multirow{2}{*}{ Chr. } & \multirow{2}{*}{$\begin{array}{c}\text { Interval } \\
\text { (cM) }\end{array}$} & \multicolumn{2}{|c|}{ Line Main Effect } & \multicolumn{2}{|l|}{ Control } & \multicolumn{2}{|c|}{$75 \mathrm{mM} \mathrm{NaCl}$} & \multicolumn{2}{|c|}{$150 \mathrm{mM} \mathrm{NaCl}$} \\
\hline & & & & & Mean & $\mathrm{RP} \%$ & Mean & RP\% & Mean & RP\% & Mean & RP\% \\
\hline \multirow{3}{*}{ GP } & & Scarlett & & & $81.5 \mathrm{sC}$ & & $93.3 \mathrm{sC}$ & & $73.3 \mathrm{sC}$ & & $77.8 \mathrm{SC}$ & \\
\hline & QGP.S42IL.4H.a & S42IL-116 & $4 \mathrm{H}$ & $1.1-40$ & 91.9 & $12.7 * *$ & 95.6 & 2.4 & 97.8 & $33.3^{* *}$ & 82.2 & 5.7 \\
\hline & QGP.S42IL.6H.c & S42IL-132 & $6 \mathrm{H}$ & 94.9-108.3 & 91.9 & $12.7 * *$ & 88.9 & -4.8 & 91.1 & $24.2 * *$ & 95.6 & $22.9 * *$ \\
\hline \multirow{3}{*}{ ShL } & & Scarlett & & & $7.2 \mathrm{SC}$ & & $9.9 \mathrm{SC}$ & & $6.2 \mathrm{SC}$ & & $5.7 \mathrm{SC}$ & \\
\hline & QShl.S42IL.2H.a & S42IL-109 & $2 \mathrm{H}$ & $33.9-62.7$ & & & 7.7 & -22.8 & 9.6 & $53.3^{* *}$ & 7.7 & $35.5 * *$ \\
\hline & QShl.S42IL.2H.c & S42IL-110 & $2 \mathrm{H}$ & $89.5-97.8$ & & & 9 & -9.6 & 9.4 & $50.8^{* *}$ & 5.4 & -5 \\
\hline \multirow{4}{*}{ RL } & & Scarlett & & & $8.1_{\mathrm{SC}}$ & & $11.3 \mathrm{sC}$ & & $7.2 \mathrm{SC}$ & & $5.8 \mathrm{SC}$ & \\
\hline & QR1.S42IL.2H.a & S42IL-109 & $2 \mathrm{H}$ & $33.9-62.7$ & & & 8.3 & $-26.8 *$ & 9.67 & $32.6^{* *}$ & 7.3 & 26.4 \\
\hline & QR1.S42IL.5H.a & S42IL-126 & $5 \mathrm{H}$ & $76.2-120.3$ & & & 10.6 & -6.6 & 7.22 & -0.91 & 8.1 & $40.9 * *$ \\
\hline & QR1.S42IL.5H.b & S42IL-176 & $5 \mathrm{H}$ & 81.3-140.1 & & & 9.4 & -16.6 & 9.86 & $35.2 * *$ & 7.5 & $30.6^{* *}$ \\
\hline \multirow{6}{*}{ SL } & & Scarlett & & & $15.4 \mathrm{SC}$ & & $21.3 \mathrm{SC}$ & & $13.5 \mathrm{SC}$ & & $11.5 \mathrm{SC}$ & \\
\hline & QS1.S42IL.2H.b & S42IL-109 & $2 \mathrm{H}$ & $33.9-62.7$ & & & 16 & -24.9 & 19.2 & $42.1^{* *}$ & 15 & $30.9 * *$ \\
\hline & QSI.S42IL.2H.d & S42IL-110 & $2 \mathrm{H}$ & $89.5-97.8$ & & & 19.4 & -8.8 & 18.3 & $35.1^{* *}$ & 11.3 & -1.2 \\
\hline & QS1.S42IL.3H.c & S42IL-115 & $3 \mathrm{H}$ & $120.7-155$ & & & 20.6 & -3 & 17.4 & 28.4 * & 9.68 & -15.5 \\
\hline & QSI.S42IL.4H.a & S42IL-116 & $4 \mathrm{H}$ & $1.1-40$ & & & 19.3 & -9.2 & 17.6 & $29.9 *$ & 8.5 & $-25.8 *$ \\
\hline & QS1.S42IL.6H & S42IL-132 & $6 \mathrm{H}$ & 94.9-108.3 & & & 19.8 & -7 & 14.8 & 9.4 & 15.1 & $31.4^{* *}$ \\
\hline \multirow{5}{*}{ SVI } & & Scarlett & & & $1289 \mathrm{sC}$ & & 1986 SC & & 992 SC & & 891 SC & \\
\hline & QSvi.S42IL.2H.b & S42IL-109 & $2 \mathrm{H}$ & $33.9-62.7$ & & & 1569 & -21 & 1537 & $55.0 * *$ & 1300 & $46.0 * *$ \\
\hline & QSvi.S42IL.4H.a & S42IL-116 & $4 \mathrm{H}$ & $1.1-40$ & & & 1842 & -7.3 & 1718 & $73.2^{* *}$ & 700 & -21.4 \\
\hline & QSvi.S42IL.6H.a & S42IL-148 & $6 \mathrm{H}$ & $0.3-11.3$ & 1004 & $-22 * *$ & 1356 & $-31.7 * *$ & 934 & -5.8 & 723 & -18.8 \\
\hline & QSvi.S42IL.6H.b & S42IL-132 & $6 \mathrm{H}$ & 94.9-108.3 & 1514 & $17.4 *$ & 1758 & -11.5 & 1348 & $36.0 *$ & 1438 & $61.5^{* *}$ \\
\hline \multirow{2}{*}{ SFW } & & Scarlett & & & $211.5_{\mathrm{SC}}$ & & 278.7 SC & & $184 \mathrm{sC}$ & & $172 \mathrm{SC}$ & \\
\hline & QSfw.S42IL.6H & S42IL-132 & $6 \mathrm{H}$ & 94.9-108.3 & & & 269.3 & -3.4 & 196.8 & 7 & 241.9 & $40.6^{* *}$ \\
\hline \multirow{2}{*}{ SDW } & & Scarlett & & & $15.4_{\mathrm{sC}}$ & & 27 & & $26.3 \mathrm{SC}$ & & $33.4 \mathrm{sC}$ & \\
\hline & QSdw.S42IL.2H & S42IL-107 & $2 \mathrm{H}$ & $12.5-41.2$ & & & 21 & -22.4 & 11.5 & $-56.0 * *$ & 40.6 & 21.8 \\
\hline \multirow{3}{*}{ RSR } & & Scarlett & & & $1.1_{\mathrm{SC}}$ & & $1.1_{\mathrm{SC}}$ & & $1.2 \mathrm{SC}$ & & $1.0 \mathrm{SC}$ & \\
\hline & QRsr.S42IL.5H.a & S42IL-125 & $5 \mathrm{H}$ & $51.5-81.3$ & 1.7 & $53.8 * *$ & 1.1 & 0 & 2.59 & $121.1^{* *}$ & 1.39 & 36.8 \\
\hline & QRsr.S42IL.5H.b & S42IL-127 & $5 \mathrm{H}$ & $138.5-162.5$ & 2.3 & $108^{* *}$ & 1.1 & -7.3 & 1.77 & $51.6^{* *}$ & 4.1 & $304.6^{* *}$ \\
\hline \multirow{2}{*}{ WCP } & & Scarlett & & & $85.5 \mathrm{sC}$ & & $90.3 \mathrm{sC}$ & & $85.8 \mathrm{sC}$ & & 80.6 sC & \\
\hline & QWc.S42IL.2H.a & S42IL-109 & $2 \mathrm{H}$ & $33.9-62.7$ & & & 87.3 & -3.3 & 92.1 & $7.3^{* *}$ & 82.5 & 2.3 \\
\hline
\end{tabular}

Where, QTL is the quantitative trail locus associated with the trait of interest, Int. lines is the introgression line that showed significant difference from Scarlett, Chr. is the chromosome name, Interval is Positions according to Comadran et al. (2012). SC is mean of Scarlett. $\mathrm{RP} \%$ is Relative performance: RP[IL] = (LS-means [IL] - LS-means [Scarlett]) $\times 100 /$ LS-means [Scarlett]. * and ${ }^{* *}$ significant and highly significant at 0.05 and 0.01 probability levels, respectively.

\subsubsection{Seed Variability and Germination Percentages}

Five QTL were detected for SSVP located on chromosomes $1 \mathrm{H}, 2 \mathrm{H}, 3 \mathrm{H}, 5 \mathrm{H}$, and $7 \mathrm{H}$. All these QTLs showed unfavorable relative performance ranging between -16.4 and $-20 \%$ as compared to Scarlett. Twelve putative QTL were detected for GP distributed on all chromosomes except $1 \mathrm{H}$. Five QTL revealed desirable increase in GP under salinity treatments with relative performance ranged between 22.9 (S42IL-132, 6H under $150 \mathrm{mM}$ $\mathrm{NaCl}$ ) and $33.3 \%$ (S42IL-116, $4 \mathrm{H}$ under $75 \mathrm{mM} \mathrm{NaCl})$.

\subsubsection{Shoot and Root Lengths}

Twenty-two QTL were found for ShL and covered the whole entire barley genome. Based on the relative performance, the QTL S42IL-109 showed strong and desirable increase in ShL by 53.3 and $35.5 \%$ as compared to Scarlett under 75 and $150 \mathrm{mM} \mathrm{NaCl}$ treatments, respectively. This QTL spans from 33.9-62.7 cM on chromosome 2H. Another QTL (S42IL110) on $2 \mathrm{H}$ spans from $89.5-97.8 \mathrm{cM}$, exhibited strong and favorable effect for ShL by $50.8 \%$ under $75 \mathrm{mM} \mathrm{NaCl}$ treatment. Likewise, the QTL analysis revealed seven QTL for $\mathrm{RL}$ distributed across chromosomes $2 \mathrm{H}, 3 \mathrm{H}, 4 \mathrm{H}, 5 \mathrm{H}$, and $7 \mathrm{H}$. The ILs, S42IL-109 (2H, 33.9-62.7 cM), S42IL-116 (4H, 1.1-40 cM), S42IL-126 (5H, 76.2-120.3 cM), and S42IL-176 $(5 \mathrm{H}, 81.3-140.1 \mathrm{cM})$ exhibited desirable positive RP\% for RL under one or both salinity treatments and ranged between 30.6 and $40.9 \%$. 


\subsubsection{Seedling Length and Seedling Vigor Index}

Thirteen QTL were detected for SL and distributed on all chromosomes except $1 \mathrm{H}$. Interestingly, four QTL at ILs, S42IL-109 (2H, 33.9-62.7 cM), S42IL-110 (2H, 89.5-97.8 cM), S42IL-115 (3H, 120.7-155 cM), and S42IL-116 (4H, 1.1-40 cM) exhibited desirable significant increase by RP ranging between 28.4 and $42.1 \%$ in SL under $75 \mathrm{mM} \mathrm{NaCl}$ conditions as compared to Scarlett. Also, two QTLs on chromosomes $2 \mathrm{H}$ and $6 \mathrm{H}$ were detected for SL, since S42IL-109 and S42IL-132 showed remarkable increase in SL by RP values 30.9 and $31.4 \%$ under $150 \mathrm{mM} \mathrm{NaCl}$ conditions. Notably, S42IL-109 showed significant increase in SL under both salinity treatments. For SVI, fourteen QTL were identified and covered the entire barley genome. Eight QTL out of them revealed desirable increase in SVI under salinity conditions by RP values ranging between 35 (S42IL-148, 6H) and 73.2\% (S42IL-116, $4 \mathrm{H}$ ) under $75 \mathrm{mM} \mathrm{NaCl}$ treatments, and between 45 (S42IL-109, 2H) and 61.5\% (S42IL-132, $6 \mathrm{H})$ under $150 \mathrm{mM} \mathrm{NaCl}$ treatments.

\subsubsection{Seedling Fresh and Dry Weights}

The QTL analysis revealed four QTL for SFW and were distributed on chromosomes $2 \mathrm{H}$ and $6 \mathrm{H}$. The strongest QTL was found in S42IL-132 located on chromosome $6 \mathrm{H}$ within the interval 94.9 and $108.3 \mathrm{cM}$, which resulted in $40.6 \%$ increase in SFW under $150 \mathrm{mM}$ $\mathrm{NaCl}$ conditions as compared to Scarlett. Only one QTL was detected for SDW of the S42IL-107 (2H, 12.5-41.2 cM), which resulted in $-56 \%$ decrease in SDW under $75 \mathrm{mM} \mathrm{NaCl}$ treatments.

\subsubsection{Root/Shoot Ratio and Water Content Percentage}

Fifteen QTL were identified for RSR and mapped on chromosomes $1 \mathrm{H}, 2 \mathrm{H}, 4 \mathrm{H}, 5 \mathrm{H}$, $6 \mathrm{H}$, and $7 \mathrm{H}$. All detected QTL showed remarkable increase in RSR under both salinity treatments. The strongest QTL effect under $75 \mathrm{mM} \mathrm{NaCl}$ conditions was found in S42IL-125 $(5 \mathrm{H}, 51.5-81.3 \mathrm{cM})$, which resulted in a $121.1 \%$ increase in RSR. While under $150 \mathrm{mM} \mathrm{NaCl}$ conditions, the strongest QTL effect was obtained for S42IL-127 (5H, 138.5-162.5 cM), which accounted for a $304.6 \%$ increase in RSR as compared to Scarlett. Two QTL were identified for WCP and distributed on chromosome 2H. The QTL in the S42IL-109 $(2 \mathrm{H}, 33.9-62.7 \mathrm{cM})$ showed remarkable increase in WCP under $75 \mathrm{mM} \mathrm{NaCl}$ conditions by RP value of $7.3 \%$ as compared to Scarlett. WCP

\subsection{QTL Detection for Salinity Tolerance Indices}

2.6.1. Germinability Tolerance Index (GTI)

Eleven QTL were identified for the two levels of GTI and distributed on chromosomes $4 \mathrm{H}, 5 \mathrm{H}, 6 \mathrm{H}$, and $7 \mathrm{H}$ (Table 5 and Figure 3). All QTLs showed a remarkable increase in GTI by $\mathrm{RP} \%$ ranged between 28.4 and $39.4 \%$ as eight QTLs under $75 \mathrm{mM} \mathrm{NaCl}$, three under $150 \mathrm{mM} \mathrm{NaCl}$, and one QTL under both treatments. The strongest QTL was found in S42 IL-148 $(6 \mathrm{H}, 0.3-11.3 \mathrm{cM})$, which resulted in a $39.4 \%$ increase in GTI as compared to Scarlett under $75 \mathrm{mM} \mathrm{NaCl}$, while under $150 \mathrm{mM} \mathrm{NaCl}$, the strongest QTL effect was obtained for S42 IL-135 (7H, 67.8-118.5 cM), which gave a 32\% increase in GTI as compared to Scarlett.

\subsubsection{Seedling Length Tolerance Index (SLTI)}

Ten QTLs were detected for SLTI and located on chromosomes $2 \mathrm{H}, 3 \mathrm{H}, 5 \mathrm{H}, 6 \mathrm{H}$, and 7H (Table 5 and Figure 3). The introgression lines (QTLs); S42 IL-109 (2H, 33.9-62.7 cM) and S42 IL-176 (5H, 81.3-140.1 cM) exhibited positive RP\% by values of (93.9 and 78.5\%) and (53.4 and $54.7 \%)$ under 75 and $150 \mathrm{mM} \mathrm{NaCl}$ treatments, respectively. 
Table 5. Identification of putative QTL associated with salinity tolerance indices at germination and seedling stages as line main effect and line by treatment interaction.

\begin{tabular}{|c|c|c|c|c|c|c|c|c|c|}
\hline \multirow{2}{*}{ QTL } & \multirow{2}{*}{ Int. Lines } & \multirow{2}{*}{ Chr. } & \multirow{2}{*}{ Interval } & \multicolumn{2}{|c|}{ Line Main Effect } & \multicolumn{2}{|c|}{ Control-75 mM NaCl } & \multicolumn{2}{|c|}{ Control-150 mM NaCl } \\
\hline & & & & Mean & $\mathbf{R P} \%$ & Mean & $\mathbf{R P} \%$ & Mean & $\mathbf{R P} \%$ \\
\hline \multicolumn{10}{|c|}{ Germination percentage tolerance index } \\
\hline & Scarlett & & & 0.81 & & 0.79 & & 0.84 & \\
\hline QGpti.S42IL.4H.a & S42IL-116 & $4 \mathrm{H}$ & $1.1-40$ & & & 1.03 & $30.0 * *$ & & \\
\hline QGpti.S42IL.4H.b & S42IL-117 & $4 \mathrm{H}$ & $17.8-49.9$ & & & 1.03 & $30.0 * *$ & & \\
\hline QGpti.S42IL.4H.c & S42IL-121 & $4 \mathrm{H}$ & $51.9-81.2$ & 1.03 & $24.7 *$ & & & 1.09 & $30.7 * *$ \\
\hline QGpti.S42IL.5H.a & S42IL-126 & $5 \mathrm{H}$ & $76.2-120.3$ & 1.06 & $30.6 * *$ & 1.07 & $35.2 * *$ & & \\
\hline Q̄Gpti.S42IL.5H.b & S42IL-176 & $5 \mathrm{H}$ & $81.3-140.1$ & 0.99 & 22.4 * & 1.01 & $28.4^{* *}$ & & \\
\hline QGpti.S42IL.5H.c & S42IL-127 & $5 \mathrm{H}$ & $138.5-162.5$ & 1.0 & $23.1 *$ & & & 1.08 & $29.2 * *$ \\
\hline QGpti.S42IL.6H.a & S42IL-148 & $6 \mathrm{H}$ & $0.3-11.3$ & & & 1.10 & $39.4 * *$ & & \\
\hline QGpti.S42IL.6H.b & S42IL-149 & $6 \mathrm{H}$ & $30-51$ & 1.01 & $24.7 *$ & 1.06 & $34.1 * *$ & & \\
\hline QGpti.S42IL.6H.c & S42IL-132 & $6 \mathrm{H}$ & 94.9-108.3 & 1.05 & $29.3^{* *}$ & 1.03 & $30.0 * *$ & 1.08 & $28.7 * *$ \\
\hline QGpti.S42IL.7H.a & S42IL-133 & $7 \mathrm{H}$ & $12.7-37.6$ & & & 1.03 & $30.2 * *$ & & \\
\hline QGpti.S42IL.7H.b & S42IL-135 & $7 \mathrm{H}$ & $67.8-118.5$ & 1.05 & $29.5^{* *}$ & & & 1.11 & $32.0^{* *}$ \\
\hline \multicolumn{10}{|c|}{ Seedling length tolerance index } \\
\hline & Scarlett & & & 0.58 & & 0.64 & & 0.54 & \\
\hline QS1ti.S42IL.2H.a & S42IL-107 & $2 \mathrm{H}$ & $12.5-41.2$ & 0.85 & $46.3 * *$ & 0.98 & $54.2 * *$ & 0.00 & \\
\hline QSlti.S42IL.2H.b & S42IL-109 & $2 \mathrm{H}$ & $33.9-62.7$ & & & 1.23 & $93.9 * *$ & 0.96 & $78.5^{* *}$ \\
\hline QSSlti.S42IL.2H.c & S42IL-153 & $2 \mathrm{H}$ & $60.7-68.6$ & & & & & 0.22 & $-59.4^{* *}$ \\
\hline QSlti.S42IL.2H.d & S42IL-110 & $2 \mathrm{H}$ & $89.5-97.8$ & & & 0.95 & $48.9^{* *}$ & & \\
\hline QS1ti.S42IL.3H.a & S42IL-111 & $3 \mathrm{H}$ & $43.1-55.2$ & & & 0.96 & $51.6 * *$ & & \\
\hline QSSlti.S42IL.3H.b & S42IL-114 & $3 \mathrm{H}$ & 75.9-144.9 & & & 1.25 & $96.3 * *$ & & \\
\hline QSlti.S42IL.5H.a & S42IL-176 & $5 \mathrm{H}$ & $81.3-140.1$ & 0.90 & $53.9 * *$ & 0.98 & $53.4^{* *}$ & 0.83 & $54.7^{* *}$ \\
\hline QSSlti.S42IL.5H.b & S42IL-127 & $5 \mathrm{H}$ & $138.5-162.5$ & & & & & 0.22 & $-58.4^{* *}$ \\
\hline QSlti.S42IL.6H & S42IL-132 & $6 \mathrm{H}$ & $94.9-108.3$ & & & & & 0.76 & $41.5^{* *}$ \\
\hline QSlti.S42IL.7H & S42IL-139 & $7 \mathrm{H}$ & $129.5-141.1$ & & & & & 0.27 & $-50.0 * *$ \\
\hline \multicolumn{10}{|c|}{ Seedling fresh weight tolerance index } \\
\hline & Scarlett & & & 0.63 & & 0.66 & & 0.62 & \\
\hline QSfwti.S42IL.2H.a & S42IL-107 & $2 \mathrm{H}$ & $12.5-41.2$ & & & & & 1.00 & $61.8 * *$ \\
\hline QSfwti.S42IL.2H.b & S42IL-109 & $2 \mathrm{H}$ & $33.9-62.7$ & 1.1 & $72.7^{* *}$ & 1.15 & $73.7^{* *}$ & 1.06 & $71.7 * *$ \\
\hline \multicolumn{10}{|c|}{ Seedling dry weight tolerance index } \\
\hline & Scarlett & & & 1.1 & & & & & \\
\hline QSdwti.S42IL.7H.a & S42IL-133 & $7 \mathrm{H}$ & $12.7-37.6$ & 1.8 & $64.2 *$ & & & & \\
\hline QSdwti.S42IL.7H.b & S42IL-137 & $7 \mathrm{H}$ & $86-127.5$ & 1.7 & $59.1 *$ & & & & \\
\hline \multicolumn{10}{|c|}{ Water content percentage tolerance index } \\
\hline & Scarlett & & & 0.92 & & 0.95 & & 0.89 & \\
\hline QWcti.S42IL.2H.a & S42IL-108 & $2 \mathrm{H}$ & $12.5-59.1$ & & & 1.03 & $8.2 * *$ & & \\
\hline QWcti.S42IL.2H.b & S42IL-109 & $2 \mathrm{H}$ & $33.9-62.7$ & 0.99 & $8.4^{* *}$ & 1.05 & $10.9 * *$ & & \\
\hline QWcti.S42IL.2H.c & S42IL-153 & $2 \mathrm{H}$ & $60.7-68.6$ & & & & & 0.78 & $-12.4^{* *}$ \\
\hline QWcti.S42IL.3H.a & S42IL-111 & $3 \mathrm{H}$ & $43.1-55.2$ & & & 1.03 & $8.7^{* *}$ & & \\
\hline QWcti.S42IL.3H.b & S42IL-114 & $3 \mathrm{H}$ & $75.9-144.9$ & & & 1.04 & $9.9 * *$ & & \\
\hline QWcti.S42IL.4H.a & S42IL-116 & $4 \mathrm{H}$ & $1.1-40$ & & & 1.03 & $8.4^{* *}$ & & \\
\hline QW cti.S42IL.4H.b & S42IL-146 & $4 \mathrm{H}$ & $55.7-81.2$ & & & 1.03 & $8.8 * *$ & & \\
\hline QWcti.S42IL.5H & S42IL-147 & $5 \mathrm{H}$ & $73.3-81.3$ & & & 1.05 & $10.0^{* *}$ & & \\
\hline QWcti.S42IL.6H.a & S42IL-148 & $6 \mathrm{H}$ & $0.3-11.3$ & 0.99 & $7.6 *$ & 1.04 & $8.9^{* *}$ & & \\
\hline QWhcti.S42IL.6H.b & S42IL-129 & $6 \mathrm{H}$ & $47.5-79.6$ & & & 1.03 & $7.9 * *$ & & \\
\hline
\end{tabular}

Where, QTL is the quantitative trail locus associated with trait of interest, Int. lines is the introgression line that showed significant difference from Scarlett, Chr. is the chromosome name, Interval is Positions according to Comadran et al. (2012). SC is mean of Scarlett. $\mathrm{RP} \%$ is Relative performance: $\mathrm{RP}[\mathrm{IL}]=(\mathrm{LS}-\mathrm{means}$ [IL]-LS-means [Scarlett] $) \times 100 /$ LS-means [Scarlett]. ${ }^{*}$ and ${ }^{* *}$ significant and highly significant at 0.05 and 0.01 probability levels, respectively. 


\subsubsection{Seedling Fresh (SFWTI) and Dry Weights Tolerance Indices (SDWTI)}

Two QTL were found for SFWTI and mapped on chromosome 2H (Table 5 and Figure 3). The strongest QTL was found in S42 IL-109 (2H, 33.9-62.7 cM) and showed IL main effect. Interestingly, the exotic alleles at this locus increased SFWTI by RP\% values of 73.7 and $71.7 \%$ under both treatments, respectively. In addition, the second QTL was found for the IL S42 IL-107 $(2 \mathrm{H}, 12.5-41.2 \mathrm{cM})$, which showed increase in SFWTI under $150 \mathrm{mM} \mathrm{NaCl}$ conditions as compared to Scarlett. Two QTL for SDWTI as line main effect and mapped on chromosome 7H. Both QTL QSdwti.S42IL.7H.a and QSdwti.S42IL.7H.b displayed desirable relative performance with values of 64.2 and $59.1 \%$, respectively.

\subsubsection{Water Content Percentage Tolerance Index (WCPTI)}

Ten QTLs were detected for WCPTI and distributed on chromosomes $2 \mathrm{H}, 3 \mathrm{H}, 4 \mathrm{H}, 5 \mathrm{H}$, and $6 \mathrm{H}$ (Table 5 and Figure 3). All these QTLs exhibited ILs by treatment interaction, as nine QTLs under $75 \mathrm{mM} \mathrm{NaCl}$ conditions and one QTL under $150 \mathrm{mM} \mathrm{NaCl}$ conditions. The strongest QTL effect was found in S42 IL-109 $(2 \mathrm{H}, 33.9-62.7 \mathrm{cM})$, which resulted in a $10.9 \%$ increase in WCPTI, followed by S42 IL-147 $(5 \mathrm{H}, 73.3-81.3 \mathrm{cM})$, which gave a $10 \%$ increase in WCPTI under $75 \mathrm{mM} \mathrm{NaCl}$ conditions. Additionally, the only QTL that was detected under $150 \mathrm{mM} \mathrm{NaCl}$ conditions was found in S42 IL-153 (2H, 60.7-68.6 cM), which resulted in a decrease in WCPTI by $\mathrm{RP} \%$ value of $-12.4 \%$.

\section{Discussion}

Germination and seedling growth are considered critical stages in the plant life cycle, especially under unfavorable environmental conditions [27-29]. In many production areas worldwide, particularly arid and semi-arid environments, barley is affected by salinity stress, which reduces both grain yield and quality [30,31]. However, salinity tolerance in crops is a complex quantitative trait both genetically and physiologically, and any induced change by salinity is modulated by changes in gene expression [32,33]. So, uncovering and understanding the genetic makeup is of paramount importance to improving salt tolerance. Identifications of desirable candidate genes or QTL associated with salinity tolerance is becoming increasingly important for plant breeders and consequently for farmers. Such stress tolerance improvement can be achieved through genetic variation that is present in crop wild relatives, which can be a major source in providing the required genes since they show a huge allelic variation, often much wider than within a crop gene pool [21]. The current study aimed at detecting QTL effects of the exotic alleles in a set of 50 ILs carrying ISR42-8 introgressions in the Scarlett background to salinity tolerance at germination and seedling phases. Since the wild barley accession ISR42-8 contains detrimental alleles for both agronomic and adaptive traits, the $\mathrm{S} 42$ population and its ILs displayed transgression segregations for these traits under control and adverse conditions, referring to presence of the valuable alleles in the wild gene pool [34-40].

In the current study, salinity stress significantly affected barley seed germination process and seedling growth-related traits, causing a clear reduction in all traits, except MGT, RSR, and SDW which were increased in most of the ILs, and this is because of the adverse impacts of salinity in barley growth [41]. The high salinity treatment applied in this study $(150 \mathrm{mM} \mathrm{NaCl})$ caused a $11.3 \%$ reduction in GP. Angessa et al. [42] reported a $18 \%$ reduction in GP of barley seeds germinated on $150 \mathrm{mM} \mathrm{NaCl}$. The observed reduction in germination, may be attributed to a salty environment that increases the osmotic pressure that creates a condition similar to drought, therefore the seeds were exposed to salt-induced physiological drought stress. This process impairs the ability of seeds to absorb water from the germination medium, hence prolonging or even inhibiting seed imbibition and subsequently germination and plant growth $[43,44]$. We demonstrated a wide range of salinity tolerance in the 50 S42ILs at germination stage. The S42IL-148 is a salinity sensitive genotype, which had the lowest GP of $57.8 \%$ with a reduction of $25.7 \%$ compared to Scarlett in $150 \mathrm{mM} \mathrm{NaCl}$ treatment. In contrast, some S42ILs such as S42IL-122, S42IL-118, and S42IL-109 were less affected by severe salt treatment and had high germinability and took 
less time to germinate under salinity conditions compared to Scarlett, indicating their osmotolerance during germination stage. This salt-tolerance may be due to that the seeds increased their osmotic potential through sodium uptake from the germination medium that led to absorbing more water under salinity stress [45].

In addition, remarkable differences for ShL, RL, SL, RSR, SFW, SDW, and WCP were detected amongst S42Ils set under control and salinity conditions, referring to the segregation of selected traits across 50 ILs. We found that ILs S42IL-109, S42 IL-120, S42 IL-125, S42 IL-126, S42 IL-127, S42IL-132, S42 IL-148, and S42IL-176 showed significant superiority in seedling growth-related traits under both salinity treatments compared to Scarlett, indicating osmotolerance at seedling phase. This result was confirmed by salinity tolerance indices. Furthermore, increasing RSR under salinity conditions may be attributed to the rapid reduction of shoot dry matter production for consequent shortening shoot length and elongating roots for searching water [46]. These salt-tolerant ILs could be suggested to be used in breeding programs to develop new elite barley cultivars. Consistent with our findings, different parameters related to seed germination and seedling growth were significantly affected by salt stress $[15,16,18,47-49]$.

The significant differences, which were observed among treatments and for $\mathrm{G}$ by $\mathrm{T}$ interactions, referred to the obvious effect of salt stress on the tested genotypes, which responded differently to the levels of salt concentration. Such differences have been observed for the same group of S42ILs under different environmental conditions such as drought and nutrient deficiency [21,35,37-39,47]. Moreover, this noticeable variation among the genotypes in the current study was reflected through the high estimates of broadsense heritability under salinity conditions in the current study. The resultant heritability estimates of investigated traits were high and stable across salinity treatments, which is important for selection in barley breeding programs. This finding indicates that salinity tolerance along with germination- and seedling-related biological processes are genetically controlled, which could be explained by QTL analysis. Confirming our finding, moderate to high estimates of heritability for salt-tolerance-related traits at germination and seedling stages were obtained in other reports $[10,15,16,48-51]$ and in the same S42Ils library under phosphorus deficiency [21] and water stress [35].

\subsection{S42ILs by Trait Associations}

By association analysis, altogether 104 significant line by trait associations, summarized to 90 putative QTL due to the overlapping or flanking of several introgressions in the S42IL set. At forty QTL (44.4\%), the exotic introgression alleles were associated with an improved trait performance under salinity conditions, indicating that selection for salt tolerance alleles could be achieved. Consistent with this result, Schmalenbach and Pillen [48] detected 40 QTL for eight malting quality traits using S42ILs. Also, Arifuzzaman et al. [49] identified nine QTL effects of the exotic alleles, which were verified using a library of 53 S42ILs for shoot and root traits. Naz et al. [35] detected 15 chromosomal regions where the exotic QTL alleles of the S42ILs showed improvement for root and related shoot traits under drought conditions. In contrast, Honsdorf et al. [39] found that Hsp allele had a trait reducing effect of 26 QTL out of 40 under drought stress.

\subsection{Germination Percentage Linked QTL}

The exotic alleles in the S42IL-116 (4H), S42IL-132 (6H), S42IL-122 (6H), and S42IL$136(7 \mathrm{H})$ genotypes had a positive effect on the germination performance under salinity conditions as line main and line by salinity interactions effects. These genotypes exceeded Scarlett in the germination percentage under salinity conditions by $33 \%$. To our knowledge, the current study is the first report that has evaluated S42ILs for germination under salinity conditions, hence, we could not detect corresponding QTL for the trait performance in the S42IL library or even S42 population. Mano and Takeda [17] detected significant QTL for salt tolerance at germination on chromosomes $4 \mathrm{H}, 5 \mathrm{H}, 6 \mathrm{H}$, and $7 \mathrm{H}$ using two doubled haploid barley populations derived from the crosses, Steptoe/Morex and Harrington/TR306. 
In addition, unfavorable effects of the Hsp allele in the S42IL-107 on chromosome $2 \mathrm{H}$ $(12.5-41.2 \mathrm{cM})$ on GP under both control and salinity conditions were observed. Angessa et al. [42] identified two QTL on 2HL (156-160.2 cM) linked with GP in 150 and $300 \mathrm{mM}$ $\mathrm{NaCL}$ in barley.

\subsection{Seedling Growth-Related Traits Linked QTL}

In most cases, the exotic alleles of the detected QTL had unfavorable effects on seedling growth traits under salinity conditions. Several ILs exhibited pleiotropic effects, but few showed a desirable performance. Interestingly, a genomic region within the interval 33.9$62.7 \mathrm{cM}$ on chromosome $2 \mathrm{H}$ in the S42IL-109 was associated with ShL, RL, SL, SVI, and WCP. The exotic alleles at this QTL showed an exceptional desirable performance under salinity conditions compared to Scarlett. Naz et al. [35] found that the genotype S42IL109 was significantly linked to root dry weight and tillers number under drought stress. Soleimani et al. [21] found that the Hsp allele in line S42IL-109 increased shoot:root length ratio by $30.13 \%$ under phosphorus deficiency. Additionally, Honsdorf et al. [39] stated that this genotype was associated with reducing plant height along with biological and grain yields under drought conditions. In another study, Arifuzzaman et al. [49] reported that this genotype revealed significant decrease in plant height as compared to Scarlett under contrasting water regimes conditions due to the contribution of the Hsp alleles. Sayed et al. [40] detected a QTL QRL.S42-2H (25-7-30.2 cM) for RL at seedling stage and the Hsp alleles increased RL by value of $26.4 \%$ compared to Scarlett. Based on the above results, this genomic region may have genetic factors that influence seedling growth-related traits in the S42IL-109.

Similarly, the genotype S42IL-176 bore a QTL contributing in increasing RL by 35.2 and $30.6 \%$ in the 75 and $150 \mathrm{mM} \mathrm{NaCl}$ treatment induced, respectively. This QTL (QRI.S42IL.5H.b) locates between $81.3-140.1 \mathrm{cM}$ on chromosome $5 \mathrm{H}$ and co-locates to QYld.S42.5H, QTgw. $S 42.5 \mathrm{H}$, and QSpad.S42.5H as reported by Zahn et al. [38] and was very close to the QRL.S42$5 H(150-162 \mathrm{cM})$ as reported by Sayed et al. [40]. Naz et al. [26,35] found that S42IL-176 was associated with root-related traits including RL under drought stress. Also, Soleimani et al. [21] stated that this genotype associated significantly with RL under phosphorus deficiency. Interestingly, the VrnH1 gene, which spans between $94.95-126.76 \mathrm{cM}$, was significantly associated with RL, and the Hsp alleles displayed about a $9 \%$ increase in RL [49]. Similarly, Sayed et al. [36] detected a QTL on 5H (95 cM), where the exotic allele enhanced proline content by $54 \%$.

A QTL on $6 \mathrm{H}(94.9-108.3 \mathrm{cM})$ showed pleiotropic effects and was linked to increasing each of SL, SVI, SFW, and GP in the IL S42IL-132 under $150 \mathrm{mM} \mathrm{NaCl}$ treatment. This IL seems to be a promising genomic region carrying a valuable novel allele for salinity tolerance. Also, the ILs S42 IL-141 and S42 IL-143 on 1H showed favorable line main effect of RSR, these two lines harboring a Pyrroline-5-carboxylate synthase1-P5cs1 allele derived from the wild barley accession ISR42-8 which showed high proline accumulation [50], and displayed less severe wilting under drought stress [25].

By contrast, the detected QTL on chromosome $2 \mathrm{H}$ between $12.5-41.2 \mathrm{cM}$ in the S42IL107 showed unfavorable performance of traits GP, SL, SVI, SFW, and SDW under control and salinity conditions, which displayed high reduction percentages. This genotype reduced each number of grains per spike, biomass, grains weight per spike, plant height, and heading time under drought stress [39]. Also, this genotype was associated with reducing grain yield, grains per spike, and increasing chlorophyll content under low nitrogen input [38]. Interestingly, in the S42IL-107, the Hsp allele had negative effects on biomass, which led to $43 \%$ loss in biomass in the adult plants [39], while at the juvenile development stage, this genotype showed increase in biomass production under severe drought stress [37]. Xu et al. [51] identified a significant QTL for salinity tolerance on chromosome $2 \mathrm{H}$ at a position of $14.7 \mathrm{cM}$. Notably, this genotype contains the flowering gene $\mathrm{Ppd}-\mathrm{H} 1$ that causes early flowering in barley [39]; however, it seems to have additional effects on seedling-related traits. Similarly, the exotic alleles in the S42IL-153 on 2H 
(60.7-68.6 cM) had undesirable effects on ShL, RL. SL, SVI, SFW, and WCP performance under salinity conditions. This location was associated with the reduction of nitrogen and chlorophyll contents in barley ILs [24].

The present findings also brought out conclusive evidence for the genetic control of salinity tolerance indices of the traits GP, SL, SFW, SDW, and WCP among the 50 ILs, which was reflected by the high heritability estimates and the wide range of STIs that was observed among the genotypes. Additionally, this suggestion was confirmed by the least square means between ILs and Scarlett through Dunnett test. Across and under salinity treatments, the QTL in the ILs S42IL-121, S42IL-126, S42IL-127, S42IL-132, and S42IL-135 revealed the highest favorable RP\% compared to Scarlett. According to STI, these genotypes are salinity tolerant at germination stage. In addition, the ILs S42IL-109, S42IL-132, and S42IL-176 exhibited the highest salinity tolerance for SL in $150 \mathrm{mM} \mathrm{NaCl}$ treatment. Likewise, the S42IL-109 and S42IL-148 revealed desirable salinity tolerance index for WCP. Our findings agreed with other studies, Thabet et al. [52] and Mwando et al. [10] detected genes associated with salt-tolerance index at germination and seedling stage in barley.

\subsection{QTL Validation for Salt Tolerance}

Recently, Sayed et al. [53] evaluated the S42 population for grain weight, and its attributes under severe salinity conditions in Egypt, and detected 49 QTL for grain weight, its attributes, and their salinity tolerance indices. We validated seven exotic QTL alleles in the 50 ILs set used in the current study. The ILs S42IL-127 (5H, 138.5-162.5 cM) and S42IL-139 (7H, 129.5-141.1 cM) were associated with reducing ShL and corresponding to the QTL qPH.5H.b (AF043094A, 5H, $156 \mathrm{cM})$ and $q$ PH.7H (bPb-1793, 7H, $137.2 \mathrm{cM})$ where the Hsp alleles reduce plant height $(\mathrm{PH})$, which were detected by Sayed et al. [53]. In addition, IL S42IL-125 (5H, 51.-81.3 cM), which increases RSR, corresponds to the QTL qPH.5H.a (Bmag357, 5H, $68 \mathrm{cM}$ ) where the exotic allele increased PH [53]. Notably, this QTL harbored an Hsp allele correlated with QTL for RL, RDW, and RSR [49]. These results showed the importance of these QTL related to plant height. The QTL related to the ILs S42IL-117, 118, and 121 span 17.8-81 cM on $4 \mathrm{H}$, showed reduction in seedling growth-related traits and corresponded to HVPAZXG $(44 \mathrm{cM})$ and $b P b-6640(60.5 \mathrm{cM})$ on $4 \mathrm{H}$, in which the Hsp allele delays heading time under salinity conditions. The majority of detected novel QTL linked to SFW and SDW and their STI were mapped on 2H and $6 \mathrm{H}$ and did not show any correspondence to the QTL detected for grain and biological weights under salinity conditions. Only one QTL on 7H within the interval $86-127.5 \mathrm{cM}$ in the S42IL-137 was associated with increasing SDWTI and was corresponding to the DArT marker $b P b-5260$ for SFWTI and SDWTI were mapped on 2H. Naz et al. [49] validated nine putative exotic QTL alleles for drought tolerance in a set of ILs including S42IL-109, S42IL-137, and S42IL-148, which were associated with PH. However, many studies have been carried out at different developmental stages in barley to study the effects of salt on plant growth at genetic, physiological, and morphological levels [45,52,54-57]. The results suggest that detected QTL dominating salt tolerance at early growth stages differ from those regulating the same response in older plants, confirming that different abiotic stresses are stage-specific [58,59]. The validated QTL linked to salinity tolerance in the current study, corresponding and integrated to previously published QTL under different abiotic stresses, suggest the stability of these QTL effects across variable environmental conditions. Interestingly, the results confirmed that the QTL alleles that control salinity tolerance at germination differ from those in the seedling stage. Similar findings were obtained by Mano and Takeda [17].

Use of wild relatives to improve salinity tolerance is common in field crops. For instance, the presence of the $\mathrm{Na}^{+}$exclusion gene TmHKT1; 5-A (Nax2), encoding a $\mathrm{Na}^{+}$selective transporter, increased grain yield on saline soils in durum wheat by up to $25 \%$ [60]. Qi et al. [61] identified a novel ion transporter gene, $\mathrm{GmCHX1}$, and related its sequence alterations to salt tolerance in wild soybean. On the basis of our QTL study, several 
QTL (ILs) where the exotic Hsp allele had a desirable effect on trait performance under salinity conditions were identified. Particularly, S42IL-109 (2H), S42IL-116 (4H), S42IL-132 $(6 \mathrm{H})$, S42IL-133 $(7 \mathrm{H})$, S42IL-148 $(6 \mathrm{H})$, and S42IL-176 $(5 \mathrm{H})$ are promising candidates to improve salinity tolerance at germination and seedling stages, and these ILs might be very interesting for further breeding. Additionally, the results confirm the potentiality of the wild progenitor genes to improve barley performance under salinity conditions, which can be cloned for the most promising QTL detected in our study, as a genomic tool available for barley breeding and genetics. Honsdorf et al. [37,39], Arifuzzaman et al. [49], and Naz et al. [26] recommended using the most promising ILs such as S42Il-121 and S42IL-176 in barley breeding programs and to transfer them in the cultivated barley. von Korff et al. [62] noted the importance of the ILs in the assessment and utilization of exotic barley with the purpose to promote breeding progress and enable studies of gene function, in addition to locating new DNA markers on the genome and for fine mapping of genes.

\section{Materials and Methods}

\subsection{Plant Material and Genotyping}

Fifty wild barley ILs of the S42IL library (83 lines) and the recipient parent Scarlett were selected for the experiment. The S42IL library was developed from the advanced backcross population S42 and described in detail by Schmalenbach [47,63]. In brief, the S42ILs were originated from the cross between the German spring cultivar Scarlett (Hordeum vulgare ssp. vulgare) and the wild barley accession ISR42-8 (H. vulgare ssp. spontaneum, Koch), followed by three rounds of backcrossing to Scarlett as a recurrent parent and several rounds of self-pollination, combined with marker-assisted selection to produce a $\mathrm{BC}_{3} \mathrm{~S}_{4}$ population (83 lines). Each line includes a single marker-defined chromosomal segment of the wild barley accession ISR42-8, meanwhile the remaining part of the genome is derived from the elite barley cultivar Scarlett. The introgression lines were genotyped with Illumina 9K SNP chip and genetic map of the S42ILs library was created by Comadran et al. [64], where more details can be found. The genetic characterization of position and extent of Hsp introgressions of the complete set based on the Infinium 9k iSelect assay has been published by Honsdorf et al. [39].

\subsection{Seed Viability}

The seed viability test was carried out according to the International Seed Testing Association [65] as follow: A sample of 10 grains from each genotype replicated three times was immersed in $\mathrm{H} 2 \mathrm{O}$ for $18 \mathrm{~h}$, at a $20^{\circ} \mathrm{C}$ temperature, then the seeds were stained with 2, 3, 5 triphenyl tetrazolium chloride, by immersing seeds in $1 \%$ solution for $3 \mathrm{~h}$, in the absence of light and at a temperature of $30{ }^{\circ} \mathrm{C}$. Afterward, a longitudinal cross-section of the embryo was made to split the seed into two halves, the number of stained seeds was counted. Seed viability percentage (SVP; \%) was calculated as follow:

$$
\operatorname{SVP}(\%)=\frac{\text { Number of stained seeds }}{\text { Total number of seeds }} \times 100
$$

\subsection{Salinity Stress Treatments}

The experiment was conducted at the Leibniz Institute of Plant Genetics and Crop Plant Research (IPK), Gatersleben, Germany in a completely randomized design. A set of 45 seeds of each genotype was surface sterilized with $70 \%$ ethanol solution for one minute, and rinsed with sterile distilled water several times, then briefly blotted. The seeds were placed on two layers of filter papers (C160; Ahlstrom-Munksjö, GmbH, Dettingen, Germany) in crystal clear rectangular boxes (V3-92; Licefa GmbH \& Co. KG, Bad Salzuflen, Germany). The salinity treatments, with three replicates were conducted by watering the seeds with two different concentrations, 75 and $150 \mathrm{mM} \mathrm{NaCl}$ (Sodium chloride CELLPURE $^{\circledR} \geq 99.5 \%$, for cell culture and biochemistry, Carl Roth, GmbH, Karlsruhe, Germany), whereas deionized water was applied as a control treatment, and the seeds were placed in a versatile environmental test chamber (Model No. MLR-352-PE, Panasonic, 
Osaka, Japan) for ten days, maintained at $20 \pm 2{ }^{\circ} \mathrm{C}$ with $50 \pm 5 \%$ humidity at $12 \mathrm{~h} \mathrm{light}$ $\left(200 \mu \mathrm{mol} \mathrm{m}{ }^{-2} \mathrm{~s}^{-1}\right)$ and $12 \mathrm{~h}$ dark periods per day. The seeds were considered germinated when the radicle reached at least $2 \mathrm{~mm}$ in length and the number of the germinated seeds was counted daily after $24 \mathrm{~h}$ of incubation until the end of the experiment. The experiment was repeated twice for the salinity treatments using identical conditions, thus, a total of 135 seeds of each of the S42ILs and Scarlett were evaluated for salinity tolerance at germination and seedling stage.

\subsection{Evaluation of Germination Parameters}

Seeds were counted daily until the 10th day in order to calculate the following parameters.

1. Germination percentage (GP; \%):

$$
\text { GP }(\%)=\frac{\text { Number of germinated seeds }}{\text { Total number of sowed seeds }} \times 100
$$

2. Germination index (GI) was calculated according to Ranal [66] as follows:

$$
\mathrm{GI}=(10 \times \mathrm{N} 1)+(9 \times \mathrm{N} 2)+\ldots+(1 \times \mathrm{N} 10) ;
$$

where, N1, N2 ... N10, is the number of seeds germinated on the first, second and subsequent days until 10th day and the multipliers (i.e., 10, 9 .. etc.) are weights given to the days of the germination.

3. Mean germination time (MGT) was calculated according to Mudaris [67] as follows:

$$
\mathrm{MGT}=\Sigma(\mathrm{Ti} \times \mathrm{Ni}) / \Sigma \mathrm{Ni}
$$

where, $\mathrm{Ni}$ is number of the new germinated seeds at time Ti.

\subsection{Evaluation of Seedling Growth Parameters}

Shoot length (ShL) and root length (RL) in cm were measured manually at the tenth day of germination using a scaled ruler for five seedlings from each replicate at the end of the experiment, and both lengths were summed to obtain the total seedling length (SL; $\mathrm{cm}$ ). Root-shoot ratio (RSR) was calculated as the ratio of the RL to the ShL. The seedlings fresh weight (SFW) was recorded (g) using an ultra-micro lab balance (Sartorius AC 1215, Germany), then seedlings were dried at $80^{\circ} \mathrm{C}$ for $72 \mathrm{~h}$ to obtain the seedling dry weight (SDW). Seed vigor index (SVI) was calculated by multiplying germination percentage and seedling length [68]. Water content percentage (WCP; \%) was calculated based on the following formula:

$$
\mathrm{WCP}(\%)=\frac{(\mathrm{SFW}-\mathrm{SDW})}{\mathrm{SFW}} \times 100
$$

\subsection{Stress Tolerance Index (STI)}

In order to evaluate the growth performance and the variation among genotypes in their tolerance to salinity, stress tolerance index (STI) was employed for the following parameters; germination percentage (GPTI, as germination percentage tolerance index), seedling length (SLTI, as seedling length tolerance index), seedling fresh weight (SFWTI, as seedling fresh weight tolerance index), seedling dry weight (SDWTI, as seedling dry weight tolerance index), and water content \% (WCPTI, as water content percentage tolerance index). The salt tolerance indices (STIs) for these traits were calculated according to the below formula of Fernandez [69]:

$$
\text { STI }=\frac{\text { Trait value under salt treatment }}{\text { Trait value under control }}
$$




\subsection{Statistical Analyses}

The separate and combined analysis of variance (ANOVA) of a completely randomized experiment were performed using SAS software v. 9.2 with PROC GLM procedure [70], to test the effect of each treatment and the interaction between the IL and the treatments. Broad-sense heritability $\left(H_{b}\right)$ estimates were calculated under control and salinity conditions following Padi [71].

$$
H_{b}=\frac{\sigma_{g}^{2}}{\sigma_{p}^{2}}, \quad \sigma_{p}^{2}=\left(\sigma_{g}^{2}\right)+\left(\frac{\sigma_{e}^{2}}{r}\right)
$$

where, $\sigma_{g}^{2}$ is genotypic variance, $\sigma_{p}^{2}$ is phenotypic variance, $\sigma_{e}^{2}$ is pooled error variance, and $r$ is number of replicates.

Additionally, least squares means (Lsmeans) were calculated for each genotype using PROC GLM method of SAS software. The phenotypic Pearson Correlation matrix analysis among the traits in control and $150 \mathrm{mM} \mathrm{NaCl}$ treatments was calculated by R-studio.

\subsection{QTL Detection}

To detect putative QTL, the Dunnett test was performed using SAS software [70] to test the most significant differences between the individual introgression lines and Scarlett as a control $[36,40]$. QTL were classified according to the significance level, if the phenotypic Ls-mean of the introgression line (IL) was significantly different $(p<0.01)$ to Ls-mean of Scarlett in one or two treatments, it was considered as line $\times$ treatment interaction, while if the IL was significantly different $(p<0.05)$ to Scarlett in the three treatments or overall treatments, it was classified as a line main effect. Following Honsdorf et al. [39] and Naz et al. [35], when the S42IL shows a significant difference to Scarlett, it is assumed that a QTL is present within the Hsp introgression of that line, and if two independent S42ILs contained overlapping Hsp introgression and both lines exhibited a significant trait effect with the same sign, it is assumed they contained the same QTL. The QTL analysis was done for all investigated traits except germination index (GI) and mean germination time (MGT).

\section{Conclusions and Outlook}

At forty (44.4\%) QTL out of 90, the Hsp introgression alleles are involved in improving salinity tolerance at germination and seedling growth stage. Among them, seven exotic QTL alleles were successfully validated in wild barley ILs. However, it is desirable to evaluate the S42ILs library under saline conditions in the field for further validations in the adult plants. The present study provides new S42ILs like S42IL-109 (2H), S42IL-116 $(4 \mathrm{H})$, S42IL-132 (6H), S42IL-133 (7H), S42IL-148 (6H), and S42IL-176 (5H) as valuable genetic resources, and consequently novel QTL for further enhancement of salt tolerance at germination and seedling development stages in barley breeding. However, further studies on functional characterization by utilizing the agronomic, genetic, physiological, and biochemical indicators are needed that can facilitate and prove the identification of the salinity tolerance genes at early growth stages.

Supplementary Materials: The following are available online at https:/ / www.mdpi.com/article/ 10.3390/plants10112246/s1, Supplementary Table S1: Ls-means, standard error, minimum and maximum of studied traits under control and salinity conditions, Supplementary Table S2: Ls-means and standard error of salinity tolerance indices based on germination percentage (GP), seedling length (SL), seedling fresh weight (SFW), seedling dry weight (SDW), and water content percentage (WCP), Supplementary Table S3: Identification of putative QTL associated with salinity tolerance related traits at germination and seedling stages as line main effect and line by treatment interaction.

Author Contributions: Conceptualization, M.A.S. and A.B.; Methodology, M.A.S., R.T. and H.M.Y.; Software, A.B. and M.A.S.; Validation, M.A.S. and A.B.; Formal analysis, M.A.S., R.T. and A.B.; Investigation, M.A.S. and R.T.; Resources, K.P. and A.B.; Data curation, M.A.S., R.T. and A.B.; Writing—original draft preparation, M.A.S., R.T. and A.B.; Writing—review and editing, M.A.S., A.B., 
H.M.Y. and R.T.; Visualization, M.A.S. and R.T.; Project administration, A.B. and M.A.S. All authors have read and agreed to the published version of the manuscript.

Funding: The publication of this article was funded by the Open Access Fund of the Leibniz Association.

Institutional Review Board Statement: Not applicable.

Informed Consent Statement: Informed consent was obtained from all authors involved in the study.

Data Availability Statement: The data presented in this study are available in Supplementary Materials.

Acknowledgments: A sincere gratitude to the Ministry of Higher Education and Assiut University, Arab Republic of Egypt, for the award of a fully funded postdoctoral scholarship.

Conflicts of Interest: The authors declare no conflict of interest exists.

\section{References}

1. Ziemann, M.; Kamboj, A.; Hove, R.M.; Loveridge, S.; El-Osta, A.; Bhave, M. Analysis of the barley leaf transcriptome under salinity stress using mRNA-Seq. Acta Physiol. Plant. 2013, 35, 1915-1924. [CrossRef]

2. Long, N.V.; Dolstra, O.; Malosetti, M.; Kilian, B.; Graner, A.; Visser, R.G.F.; van der Linden, C.G. Association mapping of salt tolerance in barley (Hordeum vulgare L.). Theor. Appl. Genet. 2013, 126, 2335-2351. [CrossRef] [PubMed]

3. Shrivastava, P.; Kumar, R. Soil salinity: A serious environmental issue and plant growth promoting bacteria as one of the tools for its alleviation. Saudi J. Biol. Sci. 2015, 22, 123-131. [CrossRef] [PubMed]

4. Hassani, A.; Azapagic, A.; Shokri, N. Predicting long-term dynamics of soil salinity and sodicity on a global scale. Proc. Natl. Acad. Sci. USA 2021, 117, 33017-33027. [CrossRef] [PubMed]

5. Pirasteh-Anosheh, H.; Ranjbar, G.; Pakniyat, H.; Emam, Y. Physiological mechanisms of salt stress tolerance in plants: An overview. Plant-Environ. Interact. Responses Approaches Mitigate Stress 2015, 141-160. [CrossRef]

6. Munns, R.; Tester, M. Mechanisms of salinity tolerance. Annu. Rev. Plant Biol. 2008, 59, 651-681. [CrossRef] [PubMed]

7. Hernández, J.A.; Ferrer, M.A.; Jiménez, A.; Barceló, A.R.; Sevilla, F. Antioxidant systems and $\mathrm{O}_{2} \cdot-/ \mathrm{H}_{2} \mathrm{O}_{2}$ production in the apoplast of pea leaves. Its relation with salt-induced necrotic lesions in minor veins. Plant Physiol. 2001, 127, 817-831. [CrossRef] [PubMed]

8. Nawaz, K. Alleviation of the Adverse Effects of Salinity Stress on Maize (Zea mays L.) by Exogenous Application of Glycine; Faculty of Sciences, University of Agriculture: Faisalabad, Pakistan, 2007.

9. Moustafa, E.S.A.; El-Sobky, E.S.E.A.; Farag, H.I.A.; Yasin, M.A.T.; Attia, A.; Rady, M.O.A.; Awad, M.F.; Mansour, E. Sowing date and genotype influence on yield and quality of dual-purpose barley in a salt-affected arid region. Agronomy 2021, 11, 717. [CrossRef]

10. Mwando, E.; Angessa, T.T.; Han, Y.; Zhou, G.; Li, C. Quantitative Trait Loci Mapping for Vigour and Survival Traits of Barley Seedlings after Germinating under Salinity Stress. Agronomy 2021, 11, 103. [CrossRef]

11. Gorzolka, K.; Kölling, J.; Nattkemper, T.W.; Niehaus, K. Spatio-Temporal metabolite profiling of the barley germination process by MALDI MS imaging. PLoS ONE 2016, 11, e0150208. [CrossRef]

12. Wu, D. Genetic variation of $H v C B F$ genes and their association with salinity tolerance in Tibetan annual wild barley. PLoS ONE 2011, 6, e22938. [CrossRef]

13. Mwando, E.; Angessa, T.T.; Han, Y.; Li, C. Salinity tolerance in barley during germination-homologs and potential genes. J. Zhejiang Univ. Sci. B 2020, 21, 93-121. [CrossRef]

14. Mwando, E.; Han, Y.; Angessa, T.T.; Zhou, G.; Hill, C.B.; Zhang, X.Q.; Li, C. Genome-Wide Association Study of Salinity Tolerance During Germination in Barley (Hordeum vulgare L.). Front. Plant Sci. 2020, 11, 118. [CrossRef]

15. Askari, H.; Kazemitabar, S.K.; Zarrini, H.N.; Saberi, M.H. Salt tolerance assessment of barley (Hordeum vulgare L.) genotypes at germination stage by tolerance indices. Open Agric. 2016, 1, 37-44. [CrossRef]

16. Zaare, M.; Jafary, J. Quantitative trait loci diversity for salt tolerance at the early growth stage of barley (Hordeum vulgare L.). Crop Breed J. 2013, 3, 69-77.

17. Mano, Y.; Takeda, K. Mapping quantitative trait loci for salt tolerance at germination and the seedling stage in barley (Hordeum vulgare L.). Euphytica 1997, 94, 263-272. [CrossRef]

18. Hernandez, J.; Meints, B.; Hayes, P. Introgression Breeding in Barley: Perspectives and Case Studies. Front. Plant Sci. 2020, 11, 761. [CrossRef]

19. Nevo, E.; Chen, G. Drought and salt tolerances in wild relatives for wheat and barley improvement. Plant Cell Environ. 2010, 33, 670-685. [CrossRef]

20. Zamir, D. Improving plant breeding with exotic genetic libraries. Nat. Rev. Genet. 2001, 2, 983-989. [CrossRef]

21. Soleimani, B.; Sammler, R.; Backhaus, A.; Beschow, H.; Schumann, E.; Mock, H.P.; von Wirén, N.; Seiffert, U.; Pillen, K. Genetic regulation of growth and nutrient content under phosphorus deficiency in the wild barley introgression library S42IL. Plant Breed. 2017, 136, 892-907. [CrossRef] 
22. Hoffmann, A.; Maurer, A.; Pillen, K. Detection of nitrogen deficiency QTL in juvenile wild barley introgression lines growing in a hydroponic system. BMC Genet. 2012, 13, 88. [CrossRef]

23. Wang, G.; Schmalenbach, I.; von Korff, M.; Léon, J.; Kilian, B.; Rode, J.; Pillen, K. Association of barley photoperiod and vernalization genes with QTLs for flowering time and agronomic traits in a $\mathrm{BC}_{2} \mathrm{DH}$ population and a set of wild barley introgression lines. Theor. Appl. Genet. 2010, 120, 1559-1574. [CrossRef] [PubMed]

24. Schnaithmann, F.; Pillen, K. Detection of exotic QTLs controlling nitrogen stress tolerance among wild barley introgression lines. Euphytica 2013, 189, 67-88. [CrossRef]

25. Frimpong, F.; Windt, C.W.; van Dusschoten, D.; Naz, A.A.; Frei, M.; Fiorani, F. A Wild Allele of Pyrroline-5-Carboxylate Synthase1 Leads to Proline Accumulation in Spikes and Leaves of Barley Contributing to Improved Performance under Reduced Water Availability. Front. Plant Sci. 2021, 12, 180. [CrossRef] [PubMed]

26. Naz, A.A.; Ehl, A.; Pillen, K.; Léon, J. Validation for root-related quantitative trait locus effects of wild origin in the cultivated background of barley (Hordeum vulgare L.). Plant Breed. 2012, 131, 392-398. [CrossRef]

27. Riaz, M.; Arif, M.S.; Ashraf, M.A.; Mahmood, R.; Yasmeen, T.; Shakoor, M.B.; Shahzad, S.M.; Ali, M.; Saleem, I.; Arif, M.; et al A Comprehensive Review on Rice Responses and Tolerance to Salt Stress; Elsevier Inc.: Amsterdam, The Netherlands, 2018; ISBN 9780128143322.

28. Tuan, P.A.; Sun, M.; Nguyen, T.N.; Park, S.; Ayele, B.T. Molecular Mechanisms of Seed Germination; Elsevier Inc.: Amsterdam, The Netherlands, 2018; ISBN 9780128115251.

29. Lamichhane, J.R.; Messéan, A.; Ricci, P. Research and innovation priorities as defined by the Ecophyto plan to address current crop protection transformation challenges in France. Adv. Agron. 2019, 154, 81-152. [CrossRef]

30. Zhu, J.; Fan, Y.; Li, C.; Shabala, S.; Zhao, C.; Hong, Y.; Lv, C.; Guo, B.; Xu, R.; Zhou, M. Candidate genes for salinity tolerance in barley revealed by RNA-seq analysis of near-isogenic lines. Plant Growth Regul. 2020, 92, 571-582. [CrossRef]

31. Rajeswari, S.; Sood, N.; Swarup, T.G.; Subramanian, R. Assessing salt-stress tolerance in barley. Univ. Sci. 2019, 24, 91-109. [CrossRef]

32. Munns, R. Genes and salt tolerance: Bringing them together. New Phytol. 2005, 167, 645-663. [CrossRef]

33. Flowers, T.J. Improving crop salt tolerance. J. Exp. Bot. 2004, 55, 307-319. [CrossRef]

34. Schmalenbach, I.; Léon, J.; Pillen, K. Identification and verification of QTLs for agronomic traits using wild barley introgression lines. Theor. Appl. Genet. 2009, 118, 483-497. [CrossRef] [PubMed]

35. Naz, A.A.; Arifuzzaman, M.; Muzammil, S.; Pillen, K.; Léon, J. Wild barley introgression lines revealed novel QTL alleles for root and related shoot traits in the cultivated barley (Hordeum vulgare L.). BMC Genet. 2014, 15, 107. [CrossRef] [PubMed]

36. Sayed, M.A.; Schumann, H.; Pillen, K.; Naz, A.A.; Léon, J. AB-QTL analysis reveals new alleles associated to proline accumulation and leaf wilting under drought stress conditions in barley (Hordeum vulgare L.). BMC Genet. 2012, 13, 61. [CrossRef] [PubMed]

37. Honsdorf, N.; March, T.J.; Berger, B.; Tester, M.; Pillen, K. High-throughput phenotyping to detect drought tolerance QTL in wild barley introgression lines. PLoS ONE 2014, 9, e97047. [CrossRef]

38. Zahn, S.; Koblenz, B.; Christen, O.; Pillen, K.; Maurer, A. Evaluation of wild barley introgression lines for agronomic traits related to nitrogen fertilization. Euphytica 2020, 216, 39. [CrossRef]

39. Honsdorf, N.; March, T.J.; Pillen, K. QTL controlling grain filling under terminal drought stress in a set of wild barley introgression lines. PLoS ONE 2017, 12, e0185983. [CrossRef]

40. Sayed, M.A.; Hamada, A.; Lèon, J.; Naz, A.A. Genetic mapping reveals novel exotic QTL alleles for seminal root architecture in barley advanced backcross double haploid population. Euphytica 2017, 213, 54. [CrossRef]

41. Hessini, K.; Ferchichi, S.; Ben Youssef, S.; Werner, K.H.; Cruz, C.; Gandour, M. How does salinity duration affect growth and productivity of cultivated barley? Agron. J. 2015, 107, 174-180. [CrossRef]

42. Angessa, T.T.; Zhang, X.Q.; Zhou, G.; Broughton, S.; Zhang, W.; Li, C. Early growth stages salinity stress tolerance in CM72 $\mathrm{x}$ Gairdner doubled haploid barley population. PLoS ONE 2017, 12, e0179715. [CrossRef]

43. Parihar, P.; Singh, S.; Singh, R.; Singh, V.P.; Prasad, S.M. Effect of salinity stress on plants and its tolerance strategies: A review. Environ. Sci. Pollut. Res. 2015, 22, 4056-4075. [CrossRef]

44. Sayar, R.; Bchini, H.; Mosbahi, M.; Ezzine, M. Effects of salt and drought stresses on germination, emergence and seedling growth of Durum wheat (Triticum durum Desf.). Afr. J. Agric. Res. 2010, 5, 2008-2016.

45. Zhang, H.; Irving, L.J.; McGill, C.; Matthew, C.; Zhou, D.; Kemp, P. The effects of salinity and osmotic stress on barley germination rate: Sodium as an osmotic regulator. Ann. Bot. 2010, 106, 1027-1035. [CrossRef]

46. Bağci, S.A.; Ekiz, H.; Yilmaz, A. Determination of the salt tolerance of some barley genotypes and the characteristics affecting tolerance. Turk. J. Agric. For. 2003, 27, 253-260. [CrossRef]

47. Schmalenbach, I.; Körber, N.; Pillen, K. Selecting a set of wild barley introgression lines and verification of QTL effects for resistance to powdery mildew and leaf rust. Theor. Appl. Genet. 2008, 117, 1093-1106. [CrossRef] [PubMed]

48. Schmalenbach, I.K.P. Detection and verification of malting quality QTLs using wild barley introgression lines. Theor. Appl. Genet. 2009, 118, 1411-1427. [CrossRef]

49. Arifuzzaman, M.; Sayed, M.A.; Muzammil, S.; Pillen, K.; Schumann, H.; Naz, A.A.; Léon, J. Detection and validation of novel QTL for shoot and root traits in barley (Hordeum vulgare L.). Mol. Breed. 2014, 34, 1373-1387. [CrossRef]

50. Muzammil, S. Genetic Dissection of Shoot Traits and Proline Content under Control and Drought Conditions in Barley. Ph.D. Thesis, University of Bonn, Bonn, Germany, 2018. 
51. Xu, R. A single locus is responsible for salinity tolerance in a chinese landrace barley (Hordeum vulgare L.). PLoS ONE 2012, 7, e43079. [CrossRef]

52. Thabet, S.G.; Moursi, Y.S.; Sallam, A.; Karam, M.A.; Alqudah, A.M. Genetic associations uncover candidate SNP markers and genes associated with salt tolerance during seedling developmental phase in barley. Environ. Exp. Bot. 2021, 188, 104499. [CrossRef]

53. Sayed, M.A.; Nassar, S.M.; Moustafa, E.S.; Said, M.T.; Börner, A.; Hamada, A. Genetic Mapping Reveals Novel Exotic and Elite QTL Alleles for Salinity Tolerance in Barley. Agronomy 2021, 11, 1774. [CrossRef]

54. Ma, Y.; Shabala, S.; Li, C.; Liu, C.; Zhang, W.; Zhou, M. Quantitative trait loci for salinity tolerance identified under drained and waterlogged conditions and their association with flowering time in barley (Hordeum vulgare. L). PLoS ONE 2015, 10, e0134822 [CrossRef] [PubMed]

55. Saade, S.; Brien, C.; Pailles, Y.; Berger, B.; Shahid, M.; Russell, J.; Waugh, R.; Negrão, S.; Tester, M. Dissecting new genetic components of salinity tolerance in two-row spring barley at the vegetative and reproductive stages. PLoS ONE 2020, 15, e0236037. [CrossRef]

56. Iqbal, M.T. Physiological, Biochemical and Molecular Responses of Different Barley Varieties to Drought and Salinity. Ph.D. Thesis, University of Bonn, Bonn, Germany, 2018.

57. Zhou, G.; Johnson, P.; Ryan, P.R.; Delhaize, E.; Zhou, M. Quantitative trait loci for salinity tolerance in barley (Hordeum vulgare L.). Mol. Breed. 2012, 29, 427-436. [CrossRef]

58. Tarawneh, R.F.A.; Gutachter, J.; Pillen, K.; Doz Andreas Börner, P.; Khlestkina, E. Mapping and Identifying Genes for Drought Tolerance in Barley (Hordeum vulgare L.). Ph.D. Thesis, Martin-Luther-Universität Halle-Wittenberg, Halle, Germany, 2020.

59. Foolad, M. Comparison of salt tolerance during seed germination and vegetative growth in tomato by QTL mapping. Genome 1999, 42, 727-734. [CrossRef]

60. Munns, R.; James, R.A.; Xu, B.; Athman, A.; Conn, S.J.; Jordans, C.; Byrt, C.S.; Hare, R.A.; Tyerman, S.D.; Tester, M.; et al. Wheat grain yield on saline soils is improved by an ancestral $\mathrm{Na}+$ transporter gene. Nat. Biotechnol. 2012, 30, 360-364. [CrossRef] [PubMed]

61. Qi, X.; Li, M.W.; Xie, M.; Liu, X.; Ni, M.; Shao, G.; Song, C.; Kay-Yuen Yim, A.; Tao, Y.; Wong, F.L.; et al. Identification of a novel salt tolerance gene in wild soybean by whole-genome sequencing. Nat. Commun. 2014, 5, 4340. [CrossRef] [PubMed]

62. Von Korff, M.; Wang, H.; Léon, J.; Pillen, K. Development of candidate introgression lines using an exotic barley accession (Hordeum vulgare ssp. spontaneum) as donor. Theor. Appl. Genet. 2004, 109, 1736-1745. [CrossRef]

63. Schmalenbach, I.; March, T.J.; Pillen, K.; Bringezu, T.; Waugh, R. High-resolution genotyping of wild barley introgression lines and fine-mapping of the threshability locus thresh-1 using the illumina goldengate assay. G3 Genes Genomes Genet. 2011, 1, 187-196. [CrossRef]

64. Comadran, J. Natural variation in a homolog of Antirrhinum CENTRORADIALIS contributed to spring growth habit and environmental adaptation in cultivated barley. Nat. Genet. 2012, 44, 1388-1392. [CrossRef]

65. Ista International rules for seed testing. In 12. ISTA (1993) International Rules for Seed Testing; ISTA: Zurich, Switzerland, 1993; Volume 12, pp. 345-376.

66. Ranal, M.A.; de Santana, D.G.; Ferreira, W.R.; Mendes-Rodrigues, C. Calculando medidas de germinação e organizando planilhas eletrônicas. Rev. Bras. Bot. 2009, 32, 849-855. [CrossRef]

67. Mudaris, M.A. Notes on Various Parameter s Recording the Speed of Seed Germination. J. Agric. Trop. Subtrop. 1984, 99, 147-154.

68. Abdul-Baki, A.A.; Anderson, J.D. Vigor Determination in Soybean Seed by Multiple Criteria 1. Crop Sci. 1973, 13, 630-633. [CrossRef]

69. Fernandez, G.C.J. Effective selection criteria for assessing plant stress tolerance. In Proceedings of the International Symposium on Adaptation of Food Crops to Temperature and Water Stress, Taiwan, 13-18 August 1992; pp. 257-270. [CrossRef]

70. SAS Institute (2011). The SAS System for Windows. Release 9.2. SAS Inst., Cary, NC. 2011. Available online: http:/ / www.sciepub. com/reference/166089 (accessed on 4 July 2021).

71. Padi, F.K. Genotype $\times$ environment interaction and yield stability in a cowpea-based cropping system. Euphytica 2007, 158, 11-25. [CrossRef] 